\title{
Dopamine-Mediated Stabilization of Delay-Period Activity in a Network Model of Prefrontal Cortex
}

\author{
DANIEL DURSTEWITZ, ${ }^{1}$ JEREMY K. SEAMANS, ${ }^{1}$ AND TERRENCE J. SEJNOWSKI ${ }^{1,2}$ \\ ${ }^{1}$ Computational Neurobiology Laboratory, Howard Hughes Medical Institute, Salk Institute, La Jolla 92037; and \\ ${ }^{2}$ Department of Biology, University of California San Diego, La Jolla, California 92093
}

\begin{abstract}
Durstewitz, Daniel, Jeremy K. Seamans, and Terrence J. Sejnowski. Dopamine-mediated stabilization of delay-period activity in a network model of prefrontal cortex. J. Neurophysiol. 83: 1733-1750, 2000. The prefrontal cortex (PFC) is critically involved in working memory, which underlies memory-guided, goal-directed behavior. During working-memory tasks, PFC neurons exhibit sustained elevated activity, which may reflect the active holding of goal-related information or the preparation of forthcoming actions. Dopamine via the D1 receptor strongly modulates both this sustained (delay-period) activity and behavioral performance in working-memory tasks. However, the function of dopamine during delay-period activity and the underlying neural mechanisms are only poorly understood. Recently we proposed that dopamine might stabilize active neural representations in PFC circuits during tasks involving working memory and render them robust against interfering stimuli and noise. To further test this idea and to examine the dopamine-modulated ionic currents that could give rise to increased stability of neural representations, we developed a network model of the PFC consisting of multicompartment neurons equipped with Hodgkin-Huxley-like channel kinetics that could reproduce in vitro whole cell and in vivo recordings from PFC neurons. Dopaminergic effects on intrinsic ionic and synaptic conductances were implemented in the model based on in vitro data. Simulated dopamine strongly enhanced high, delay-type activity but not low, spontaneous activity in the model network. Furthermore the strength of an afferent stimulation needed to disrupt delay-type activity increased with the magnitude of the dopamine-induced shifts in network parameters, making the currently active representation much more stable. Stability could be increased by dopamine-induced enhancements of the persistent $\mathrm{Na}^{+}$and $N$-methyl-D-aspartate (NMDA) conductances. Stability also was enhanced by a reduction in AMPA conductances. The increase in $\mathrm{GABA}_{\mathrm{A}}$ conductances that occurs after stimulation of dopaminergic D1 receptors was necessary in this context to prevent uncontrolled, spontaneous switches into high-activity states (i.e., spontaneous activation of task-irrelevant representations). In conclusion, the dopamine-induced changes in the biophysical properties of intrinsic ionic and synaptic conductances conjointly acted to highly increase stability of activated representations in PFC networks and at the same time retain control over network behavior and thus preserve its ability to adequately respond to task-related stimuli. Predictions of the model can be tested in vivo by locally applying specific D1 receptor, NMDA, or $\mathrm{GABA}_{\mathrm{A}}$ antagonists while recording from $\mathrm{PFC}$ neurons in delayed reaction-type tasks with interfering stimuli.
\end{abstract}

\section{N T R O D U C T I O N}

The prefrontal cortex (PFC) and its dense dopaminergic input are critically involved in working-memory functions

\footnotetext{
The costs of publication of this article were defrayed in part by the payment of page charges. The article must therefore be hereby marked "advertisement" in accordance with 18 U.S.C. Section 1734 solely to indicate this fact.
}

(Brozoski et al. 1979; Fuster 1989; Goldman-Rakic 1995; Müller et al. 1998; Petrides 1995; Sawaguchi and GoldmanRakic 1994; Seamans et al. 1998). Working memory refers to the ability to hold temporally active goal-related information and to use it in preparing actions and guiding behavior. During working-memory tasks, which involve a delay component, many PFC neurons show stimulus- and/or goal-specific, sustained activity during the delay. This activity is presumed to reflect the active holding of task-related information or motor preparation while external cues are absent (Funahashi and Kubota 1994; Fuster 1989; Goldman-Rakic 1990; Quintana and Fuster 1999), and it can be maintained even in the presence of interfering stimuli (Miller et al. 1996).

Task-related electrical activity in the PFC is modulated by dopamine (DA), mainly via the D1 receptor (Sawaguchi et al. 1988, 1990a,b; Williams and Goldman-Rakic 1995). Dopaminergic midbrain neurons are activated at the onset of workingmemory tasks (Schultz et al. 1993), and DA levels in the PFC increase during delay-task performance (Watanabe et al. 1997). Blockade of the dopaminergic input to the PFC or of dopaminergic D1 receptors in the PFC disrupt delay-task performance (Brozoski et al. 1979; Sawaguchi and Goldman-Rakic 1994; Seamans et al. 1998; Simon et al. 1980). DA has been shown in vitro to influence the biophysical properties of multiple intrinsic ionic and synaptic currents of PFC neurons (Gulledge and Jaffe 1998; Kita et al. 1999; Law-Tho et al. 1994; Seamans et al. 1999; Shi et al. 1997; Yang and Seamans 1996; Zheng et al. 1999; Zhou and Hablitz 1999). However, it is unclear how these relate to DA's role in working memory. Thus although it is clear that DA plays an important role in working memory and alters the properties of PFC single neurons and synapses, its specific functions and the underlying biophysical mechanisms remain elusive.

One function of DA may be to stabilize neural representations in the PFC and thus enable PFC networks to sustain task-related activity even in the presence of interfering input (Durstewitz et al. 1999a), which could be a unique feature of prefrontal networks (Miller et al. 1996). In other words, DA might increase the robustness of (sustained) delay activity with respect to distracting input and noise. In a previous study, the general concept of DA-induced stability was explored in a simple model with leaky-integrator units that lacked detailed channel kinetics and spiking behavior (Durstewitz et al. 1999a). Here we confirm and extend the general results of this study under more realistic conditions in a network of compartmental model neurons with Hodgkin-Huxley-like channel kinetics devised to reproduce in vitro and in vivo results from 
deep layer PFC neurons. Greater physiological detail allowed dopaminergic effects on network activity to be explored in ways that were beyond the scope of the former model. In addition, we investigate the possible functional implications of the differential dopaminergic modulation of $N$-methyl-D-aspartate (NMDA) and AMPA synaptic conductances (Cepeda et al. 1992; Kita et al. 1999; Law-Tho et al. 1994; Seamans et al. 1999) and provide a functional interpretation of the DA-induced increase in $\mathrm{GABA}_{\mathrm{A}}$ currents for working-memory processes (Rétaux et al. 1991; Seamans et al. 1999; Yang et al. 1997; Zhou and Hablitz 1999).

\section{METHOD S}

\section{In vitro recordings}

To obtain voltage traces for adjustment of the model neurons, in vitro recordings from PFC layer V intrinsically bursting (IB) pyramidal cells were made. Details for recording methods can be found in Seamans et al. (1997). Briefly, the brains of male Sprague-Dawley rats (14-28 days) were rapidly dissected and immersed for $1 \mathrm{~min}$ in cold $\left(4^{\circ} \mathrm{C}\right)$ oxygenated artificial cerebrospinal fluid (ACSF). After cutting, $300-\mu \mathrm{m}$ slices containing the prelimbic/infralimbic region of the PFC were transferred to ACSF containing (in $\mathrm{mM}$ ) $126 \mathrm{NaCl}, 3 \mathrm{KCl}, 26$ $\mathrm{NaHCO}_{3}, 1.3 \mathrm{MgCl}_{2}, 2.3 \mathrm{CaCl}_{2}$, and 10 glucose at $30^{\circ} \mathrm{C}$. Thickwalled borosilicate pipettes (serial resistance $=4-25 \mathrm{M} \Omega$ for somatic recordings was $80 \%$ compensated) were filled with (in $\mathrm{mM}$ ) 130 K-gluconate, $10 \mathrm{KCl}, 1$ ethylene glycol-bis( $\beta$-aminoethyl ether)- $N$, $N, N^{\prime}, N^{\prime}$-tetraacetic acid (EGTA), $2 \mathrm{MgCl}_{2}, 2 \mathrm{NaATP}$, and $10 \mathrm{~N}$-2hydroxyethylpiperazine- $N^{\prime}-2$-ethanesulfonic acid (HEPES). Pipettes were connected to the headstage of an Axoclamp-2B or Axopatch200B amplifier (Axon Instruments) with $\mathrm{Ag} / \mathrm{AgCl}$ wire.

\section{Pyramidal cell model}

A compartmental model was developed that reproduced somatic voltage recordings from a layer V IB pyramidal cell in rat PFC (Fig. $1 A$ ). Deep layer pyramidal cells are the ones most strongly innervated by dopaminergic fibers in the rat and primate PFC and express the highest levels of mRNA for all DA receptor subtypes (Berger et al. 1988, 1991; Goldman-Rakic et al. 1992; Joyce et al. 1993; Lewis et al. 1992; Lidow et al. 1998). Furthermore they constitute the major portion of neurons exhibiting sustained delay activity (Fuster 1973). Intrinsically bursting pyramidal cells were chosen because they are the most common pyramidal cell type in the deep layers of the rat PFC as assessed by intracellular in vitro recordings $(>60 \%)$ (Yang et al. 1996). The model layer $V$ neurons consisted of a soma, a basal dendritic, a proximal and a distal apical dendritic compartment, as depicted in Fig. 1A. The cellular dimensions of the model were in agreement with a morphological reconstruction of a PFC layer $\mathrm{V}$ pyramidal cell obtained in our laboratory. (Test simulations performed with a more detailed 20-compartment model yielded the same basic results, not shown here.)

The passive properties of the model were adjusted to approximately reproduce the input resistance $\left(R_{\mathrm{IN}}\right)$, membrane time constant $\left(\tau_{\mathrm{m}}\right)$, and resting potential $\left(V_{\text {rest }}\right)$ of prefrontal IB cells recorded in vitro. The resulting values for the specific membrane resistance, membrane capacity, and cytoplasmatic (axial) resistivity were, respectively, $R_{\mathrm{m}}=30 \mathrm{k} \Omega-\mathrm{cm}^{2}, C_{\mathrm{m}}=1.2 \mu \mathrm{F} / \mathrm{cm}^{2}$, and $R_{\mathrm{i}}=150 \Omega-\mathrm{cm}$, which are well in the range of empirically derived estimations for pyramidal cells from other studies (Destexhe and Paré 1999; Spruston et al. 1994; Stuart and Spruston 1998). The leakage reversal potential $\left(E_{\text {leak }}\right)$ was $-70 \mathrm{mV}$. These values (together with the active processes) gave rise to a $V_{\text {rest }} \sim-66 \mathrm{mV}$ (matching the empirically measured mean, about $-66 \mathrm{mV}$ ), $R_{\mathrm{IN}} \sim 164 \mathrm{M} \Omega$ (empirically measured mean, $\sim 163 \mathrm{M} \Omega$ ), $\tau_{\mathrm{m}}=R_{\mathrm{m}} C_{\mathrm{m}}=36 \mathrm{~ms}$ (empirically, $\sim 33 \mathrm{~ms}$ ),
A

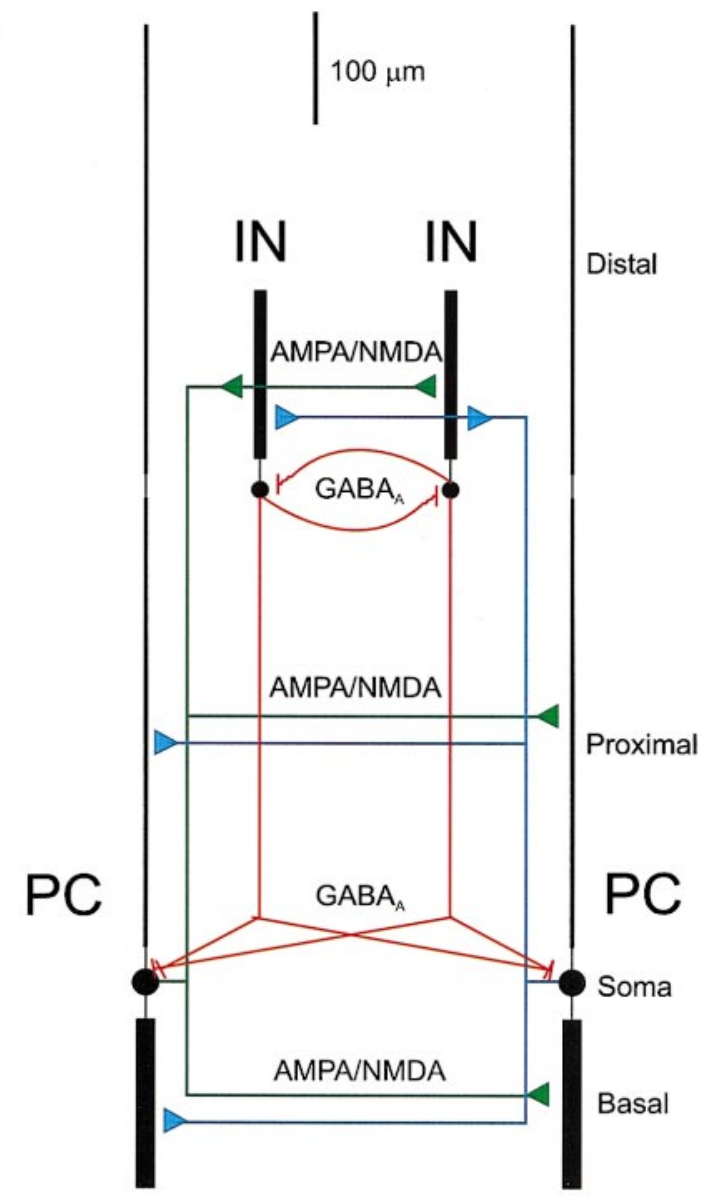

B

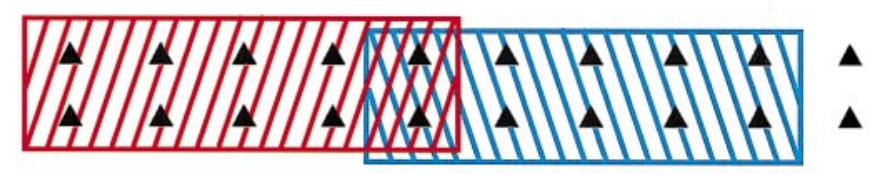

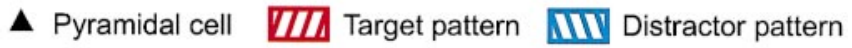

FIG. 1. Schematic of the prefrontal cortex (PFC) network model. A: compartmental representations of the pyramidal cells (PC) and the GABAergic interneurons (IN), and their synaptic interconnections in the model network. $B$ : 2 partly overlapping patterns were stored in the pyramidal cell network by connecting pyramidal cells within these patterns by high synaptic weights while connecting them to pyramidal neurons outside the pattern by low synaptic weights. One of these patterns was used as the target pattern, whereas the other was used as a distractor.

which conjointly with the active processes resulted in an effective time constant at the soma of $\sim 44 \mathrm{~ms}$, which is well within the range of recordings from IB cells in vitro (range $\sim 16-55 \mathrm{~ms}$ ). Dendritic spines were implemented by increasing the effective dendritic $C_{\mathrm{m}}$ and dividing the effective dendritic $R_{\mathrm{m}}$ by a factor of 1.92 , accounting for a $92 \%$ increase in dendritic membrane area due to spines as estimated from data of Larkman (1991; see also Rhodes and Gray 1994).

DA controls various active ionic processes in the soma and dendrites of deep layer prefrontal pyramidal cells, and as we were interested specifically in the effects of DA on network behavior, the selection of active conductances included in our model was motivated primarily by this aim. Six different ionic conductances were distributed over the soma and the dendritic compartments with densities 
TABLE 1. Compartment dimensions, maximum conductance densities, and calcium decay time constants

\begin{tabular}{|c|c|c|c|c|c|c|c|c|c|c|c|}
\hline \multirow[b]{2}{*}{$\mathrm{CT}$} & \multirow[b]{2}{*}{$l, \mu \mathrm{m}$} & \multirow[b]{2}{*}{$d, \mu \mathrm{m}$} & \multirow[b]{2}{*}{$I_{\mathrm{Na}}$} & \multirow[b]{2}{*}{$I_{\mathrm{NaP}}$} & \multicolumn{2}{|c|}{$I_{\mathrm{HVA}}$} & \multirow[b]{2}{*}{$I_{\mathrm{DR}}$} & \multicolumn{2}{|c|}{$I_{\mathrm{KS}}$} & \multirow[b]{2}{*}{$I_{\mathrm{C}}$} & \multirow[b]{2}{*}{$\tau_{\mathrm{Ca}}$} \\
\hline & & & & & $0 \% \mathrm{DA}$ & $100 \%$ DA & & $0 \% \mathrm{DA}$ & $100 \%$ DA & & \\
\hline \multicolumn{12}{|c|}{ Pyramidal cell model } \\
\hline Basal & 150.0 & 16.0 & 28.0 & 1.0 & 0.7 & 0.56 & 9.2 & 0.24 & 0.12 & 3.8 & 120.0 \\
\hline Soma & - & 23.0 & 86.0 & 2.2 & 0.34 & 0.272 & 33.8 & 0.14 & 0.07 & 2.2 & 250.0 \\
\hline Proximal & 400.0 & 2.6 & 28.0 & 1.0 & 0.7 & 0.56 & 9.2 & 0.24 & 0.12 & 3.8 & 120.0 \\
\hline Distal & 400.0 & 2.6 & 28.0 & - & 0.34 & 0.17 & 9.2 & 0.24 & 0.12 & 2.2 & 80.0 \\
\hline \multicolumn{12}{|c|}{ GABAergic interneuron model } \\
\hline Soma & - & 15.0 & 100.0 & - & - & - & 40.0 & - & - & - & - \\
\hline Dendrite & 150.0 & 10.0 & 20.0 & - & - & - & 8.0 & - & - & - & - \\
\hline
\end{tabular}

CT, compartment type (see Fig. $1 A$ ); DA, dopamine. Conductance densities are given in $\mathrm{mS} / \mathrm{cm}^{2} ; \tau_{\mathrm{Ca}}$, calcium decay time constants in ms.

estimated from empirical data. All conductance kinetics were modeled by Hodgkin-Huxley-like equations, where ionic conductance per unit area is given by a product of powers of one or two voltage-, time-, and, sometimes, $\left[\mathrm{Ca}^{2+}\right]_{\mathrm{i}}$-dependent, dimensionless gating variables and a maximum conductance density (Tables 1 and 2).

Gating variables develop in time according to the first-order differential equation $\mathrm{d} x / \mathrm{d} t=\left[x_{\infty}(V)-x(V, t)\right] / \tau_{x}(V)$, where $x_{\infty}$ is the voltage-dependent steady state and $\tau_{x}$ a voltage-dependent time constant. Table 2 provides an overview over the gating variables and their respective powers for all ionic conductances used in the present study. Voltage gradients were computed according to the spatially discrete form of the cable equation (e.g., Rall 1989).

SODIUM CURRENTS. A fast, spike-generating $\mathrm{Na}^{+}$current $\left(I_{\mathrm{Na}}\right)$ was distributed uniformly across all three dendritic compartments (Huguenard et al. 1989; Magee and Johnston 1995; Stuart and Sakmann 1994) but was given a higher density at the soma. This was done to transfer the lower threshold spike-generating mechanism of the axon (Colbert and Johnston 1996), which was not explicitly modeled and is probably partly due to much higher nodal $\mathrm{Na}^{+}$channel densities (Black et al. 1990; Westenbroek et al. 1989), to the soma. Conductance densities in the dendrites were adjusted to ensure spike backpropagation (Spruston et al. 1995b; Stuart and Sakmann 1994) with spike amplitudes and widths as recorded in vitro (Seamans et al. 1997). The biophysical description of $I_{\mathrm{Na}}$ was taken from a computational study by Warman et al. (1994) and adapted to fit kinetics determined by Cummins et al. (1994), who analyzed $\mathrm{Na}^{+}$currents in rat and human neocortical pyramidal cells.

A persistent $\mathrm{Na}^{+}$current $\left(I_{\mathrm{NaP}}\right)$ was also included in the model with kinetics modified from the fast channel to allow the persistent $\mathrm{Na}^{+}$ current to make a more significant contribution to membrane potential in the subthreshold range (cf. Alzheimer et al. 1993; Schwindt 1992; Stafstrom et al. 1985; Stuart and Sakmann 1995). Inactivation of $I_{\mathrm{NaP}}$ has been shown to contribute significantly to long-time scale adaptation in pyramidal cells (Fleidervish et al. 1996), and thus the kinetics of $I_{\mathrm{NaP}}$ also were adapted to account for much of the long-scale adaptation properties of the model neurons. $I_{\mathrm{NaP}}$ was limited to the

TABLE 2. Gating variables for all ion channels used in the present model

\begin{tabular}{|c|c|c|c|c|c|}
\hline Conductance Type & $\begin{array}{l}\text { Gating } \\
\text { Variable } x\end{array}$ & $\alpha$ & $\beta$ & $x_{\infty}$ (Steady-State Gating) & $\tau_{\mathrm{x}}, \mathrm{ms}$ \\
\hline \multicolumn{6}{|l|}{ Pyramidal cell model } \\
\hline \multirow[t]{2}{*}{$I_{\mathrm{Na}}$} & $m^{3}$ & $\begin{array}{l}{\left[-0.2816\left(V_{\mathrm{m}}+28\right)\right]} \\
\quad \times\left[-1+\exp \left(-\left(V_{\mathrm{m}}+28\right) /\right.\right. \\
\quad 9.3)]^{-1}\end{array}$ & $\begin{array}{l}{\left[0.2464\left(V_{\mathrm{m}}+1\right)\right]} \\
\quad \times\left[-1+\exp \left(\left(V_{\mathrm{m}}+1\right) / 6\right)\right]^{-1}\end{array}$ & $\alpha /(\alpha+\beta)$ & $1 /(\alpha+\beta)$ \\
\hline & $h$ & $0.098 \times \exp \left(-\left(V_{\mathrm{m}}+43.1\right) / 20\right)$ & $1.4 /\left[1+\exp \left(-\left(V_{\mathrm{m}}+13.1\right) / 10\right)\right]$ & $\alpha /(\alpha+\beta)$ & $1 /(\alpha+\beta)$ \\
\hline \multicolumn{6}{|c|}{ 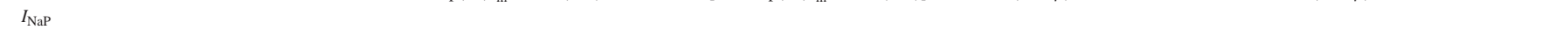 } \\
\hline \multirow[t]{2}{*}{$0 \% \mathrm{DA}$} & $m$ & 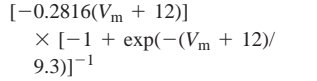 & $\begin{array}{l}{\left[0.2464\left(V_{\mathrm{m}}-15\right)\right]} \\
\quad \times\left[-1+\exp \left(\left(V_{\mathrm{m}}-15\right) / 6\right)\right]^{-1}\end{array}$ & $\alpha /(\alpha+\beta)$ & $1 /(\alpha+\beta)$ \\
\hline & $h$ & $\begin{array}{l}2.8 \times 10^{-5} \times \exp \left(-\left(V_{\mathrm{m}}\right.\right. \\
\quad+42.8477) / 4.0248)\end{array}$ & $\begin{array}{l}0.02 \times\left[1+\exp \left(-\left(V_{\mathrm{m}}\right.\right.\right. \\
\quad-413.9284) / 148.2589)]^{-1}\end{array}$ & $\alpha /(\alpha+\beta)$ & $1 /(\alpha+\beta)$ \\
\hline \multirow[t]{2}{*}{$100 \% \mathrm{DA}$} & $m$ & $\begin{array}{l}{\left[-0.2816\left(V_{\mathrm{m}}+17\right)\right]} \\
\quad \times\left[-1+\exp \left(-\left(V_{\mathrm{m}}+17\right) /\right.\right. \\
\quad 9.3)]^{-1}\end{array}$ & $\begin{array}{l}{\left[0.2464\left(V_{\mathrm{m}}-10\right)\right]} \\
\quad \times\left[-1+\exp \left(\left(V_{\mathrm{m}}-10\right) / 6\right)\right]^{-1}\end{array}$ & $\alpha /(\alpha+\beta)$ & $1 /(\alpha+\beta)$ \\
\hline & $h$ & $\begin{array}{l}2.0 \times 10^{-5} \times \exp \left(-\left(V_{\mathrm{m}}\right.\right. \\
\quad+42.8477) / 4.0248)\end{array}$ & $\begin{array}{l}0.014286 \times\left[1+\exp \left(-\left(V_{\mathrm{m}}\right.\right.\right. \\
\quad-413.9284) / 148.2589)]^{-1}\end{array}$ & $\alpha /(\alpha+\beta)$ & $1 /(\alpha+\beta)$ \\
\hline \multirow[t]{2}{*}{$I_{\mathrm{HVA}}$} & $u^{2}$ & - & - & {$\left[1+\exp \left(-\left(V_{\mathrm{m}}+24.6\right) / 11.3\right)\right]^{-1}$} & $1.25 \times \operatorname{sech}\left(-0.031\left(V_{\mathrm{m}}+37.1\right)\right)$ \\
\hline & $v$ & - & - & $\left.\left[1+\exp \left(V_{\mathrm{m}}+12.6\right) / 18.9\right)\right]^{-1}$ & 420.0 \\
\hline$I_{\mathrm{DR}}$ & $n^{4}$ & $\begin{array}{l}{\left[-0.018\left(V_{\mathrm{m}}-13\right)\right]} \\
\quad \times\left[-1+\exp \left(-\left(V_{\mathrm{m}}-13\right) / 25\right)\right]^{-1}\end{array}$ & $\begin{array}{l}{\left[0.0054\left(V_{\mathrm{m}}-23\right)\right.} \\
\quad \times\left[-1+\exp \left(\left(V_{\mathrm{m}}-23\right) / 12\right)\right]^{-1}\end{array}$ & $\alpha /(\alpha+\beta)$ & $1 /(\alpha+\beta)$ \\
\hline \multirow[t]{2}{*}{$I_{\mathrm{KS}}$} & $a$ & - & - & {$\left[1+\exp \left(-\left(V_{\mathrm{m}}+34\right) / 6.5\right)\right]^{-1}$} & 6.0 \\
\hline & $b$ & - & - & {$\left[1+\exp \left(\left(V_{\mathrm{m}}+65\right) / 6.6\right)\right]^{-1}$} & $\begin{array}{l}200+3200 \\
\quad \times\left[1+\exp \left(-\left(V_{\mathrm{m}}+63.6\right) / 4\right)\right]^{-1}\end{array}$ \\
\hline$I_{\mathrm{C}}$ & $c^{2}$ & $\begin{array}{l}{\left[-0.00642 V_{\mathrm{s}}-0.1152\right]} \\
\quad \times\left[-1+\exp \left(-\left(V_{\mathrm{s}}\right.\right.\right. \\
\quad+18) / 12)]^{-1} \\
\quad \text { with } V_{\mathrm{s}}=V_{\mathrm{m}}+40 \log _{10}\left([\mathrm{Ca}]_{\mathrm{i}}\right)\end{array}$ & $1.7 \times \exp \left(-\left(V_{\mathrm{s}}+152\right) / 30\right)$ & $\alpha /(\alpha+\beta)$ & $\max (1 /(\alpha+\beta), 1.1)$ \\
\hline \multicolumn{6}{|l|}{$\begin{array}{l}\text { GABAergic interneuron } \\
\text { model }\end{array}$} \\
\hline \multirow[t]{2}{*}{$I_{\mathrm{Na}}$} & $m^{3}$ & $4.2 \times \exp \left(\left(V_{\mathrm{m}}+34.5\right) / 11.57\right)$ & $4.2 \times \exp \left(-\left(V_{\mathrm{m}}+34.5\right) / 27\right)$ & $\alpha /(\alpha+\beta)$ & $1 /(\alpha+\beta)$ \\
\hline & $h$ & $0.09 \times \exp \left(-\left(V_{\mathrm{m}}+45\right) / 33\right)$ & $0.09 \times \exp \left(\left(V_{\mathrm{m}}+45\right) / 12.2\right)$ & $\alpha /(\alpha+\beta)$ & $1 /(\alpha+\beta)$ \\
\hline$I_{\mathrm{DR}}$ & $n^{4}$ & $0.3 \times \exp \left(\left(V_{\mathrm{m}}+35\right) / 10.67\right)$ & $0.3 \times \exp \left(-\left(V_{\mathrm{m}}+35\right) / 42.68\right)$ & $\alpha /(\alpha+\beta)$ & $1 /(\alpha+\beta)$ \\
\hline
\end{tabular}

$V_{\mathrm{m}}$, membrane potential in $\mathrm{mV} ;[\mathrm{Ca}]_{\mathrm{i}}$, intracellular calcium concentration in $\mu \mathrm{mol} / \mathrm{l}$. 
soma and the proximal dendrites and was not included into the distal apical dendritic compartment, in agreement with electrophysiological data from Stuart and Sakmann (1995) and immunocytochemical data from Westenbroek et al. (1989). According to Schwindt and Crill (1995) and Mittmann et al. (1997), however, $I_{\mathrm{NaP}}$ might be present as far distal as $300-500 \mu \mathrm{m}$ from the soma, which is still in agreement with the longitudinal extent of the proximal dendritic compartment in the present model. The reversal potential for $\mathrm{Na}^{+}$currents was fixed at $E_{\mathrm{Na}}=+55 \mathrm{mV}$.

CALCIUM CURRENTS AND CALCIUM ACCUMULATION. The biophysical description of a high-voltage-activated (HVA) $\mathrm{Ca}^{2+}$ current was taken from Brown et al. (1993), who studied these currents in dissociated rat sensorimotor cortex pyramidal cells. For simplicity we did not distinguish between $\mathrm{L}$ - and $\mathrm{N}$-type $\mathrm{Ca}^{2+}$ currents, which according to Brown et al. (1993) have the same activation kinetics, but assumed that the HVA $\mathrm{Ca}^{2+}$ current implemented in the model represents a mixture of the two. Immunocytochemical, $\mathrm{Ca}^{2+}$ influx, and electrophysiological data suggest that HVA $\mathrm{Ca}^{2+}$ channels are highly clustered in the proximal dendrites around the soma, are present with significant densities along the apical stem, but are quite low in density in the distal apical tuft, in neocortical including prefrontal pyramidal cells (Hell et al. 1993; Schiller et al. 1995; Seamans et al. 1997; Westenbroek et al. 1990, 1992). Densities of the HVA channel in the present study were adjusted accordingly (Table 1).

Extracellular and intracellular calcium concentrations initially were set to $\left[\mathrm{Ca}^{2+}\right]_{\mathrm{o}}=2 \mathrm{mmol} / \mathrm{l}$ and $\left[\mathrm{Ca}^{2+}\right]_{\mathrm{i}}=50 \mathrm{nmol} / \mathrm{l}$, respectively, in accordance with the in vitro recording conditions under which whole cell voltage traces for comparison were obtained. Whereas extracellular calcium was assumed to be constant, intracellular calcium in each compartment was regulated by a simple first-order differential equation of the form $\mathrm{d}\left[\mathrm{Ca}^{2+}\right]_{\mathrm{i}} / \mathrm{d} t=-\phi_{i} \times I_{\mathrm{HVA}} /\left(F \times V_{\text {shell }, i}\right)+$ $\left(\left[\mathrm{Ca}^{2+}\right]_{\text {rest }}-\left[\mathrm{Ca}^{2+}\right]_{\mathrm{i}}\right) / \tau_{\mathrm{Ca}}$, where $F$ is Faraday's constant, $V_{\text {shell }, i}$, which depends on the dimensions of compartment $i$, is the volume of an intracellular perimembrane shell of thickness $d_{\text {shell }}=2.0 \times 10^{-4}$ $\mu \mathrm{m}, I_{\mathrm{HVA}}$ is the total $\mathrm{Ca}^{2+}$ current for that compartment, and $\phi_{i}$ is a calcium accumulation factor that was set to $386 \times 10^{-9}$ for the soma and to $965 \times 10^{-9}$ for the dendrites to reflect the steeper rise of perimembrane $\mathrm{Ca}^{2+}$ in the dendrites due to their much lower volume [These values were determined so that the calcium concentration during a train of action potentials approximately matched data from Helmchen et al. (1996)]. In the second term, which regulates calcium decay, $\left[\mathrm{Ca}^{2+}\right]_{\text {rest }}=50 \mathrm{nmol} / \mathrm{l}$ (cf. Sah 1992; Yamada et al. 1989) is the resting concentration, which is equivalent to the initial concentration, and $\tau_{\mathrm{Ca}}$ is the time constant with which calcium approaches the resting value. The calcium decay time constants for each compartment are given in Table 1. Decay time constants for $\mathrm{Ca}^{2+}$ in the dendrites are in the range reported by Helmchen et al. (1996) for rat neocortical layer $\mathrm{V}$ pyramidal neurons at $37^{\circ} \mathrm{C}$. A higher time constant was assumed for the soma (cf. Schiller et al. 1995; Yuste et al. 1994). The reversal potential of $\mathrm{Ca}^{2+}$ currents was determined by the Nernst equation, $E_{\mathrm{Ca}}=12.5 \times \ln \left(\left[\mathrm{Ca}^{2+}\right]_{\mathrm{o}} /\left[\mathrm{Ca}^{2+}\right]_{\mathrm{i}}\right)$.

POTASSIUM CURRENTS AND POTASSIUM ACCUMULATION. The Hodgkin-Huxley-like formulas for the delayed rectifier (DR) channel were taken from a computational study by Warman et al. (1994) on hippocampal neurons. Following Rhodes and Gray (1994), the deactivation of the DR was sped up by 1.5 to better reproduce spike repolarization observed in PFC IB neurons in vitro. The distribution of DR conductance densities matched that of the fast $\mathrm{Na}^{2+}$ current (Table 1).

A slowly inactivating $\mathrm{K}^{+}$current $\left(I_{\mathrm{KS}}\right)$ is present in PFC pyramidal neurons (Hammond and Crépel 1992; Yang and Seamans 1996) and was included in the model. The formulation of $I_{\mathrm{KS}}$ was taken from Wang (1993), based on a description by Huguenard and Prince (1991) and data obtained by Spain et al. (1991) in layer V sensorimotor cortex pyramidal cells. Without specific knowledge of the distribution of $I_{\mathrm{KS}}$ in cortical neurons, we assumed uniform densities in the dendrites but a lower density at the soma, similar to the lower somatic $I_{\mathrm{A}}$ densities that have been described in hippocampal neurons (Hoffman et al. 1997).

A fast $\mathrm{BK} \mathrm{Ca}^{2+}$ - and voltage-dependent C-type $\mathrm{K}^{+}$current $\left(I_{\mathrm{C}}\right)$ was also included in the model. The biophysical properties of this current were modified from Warman et al. (1994). Activation of this channel depended logarithmically on internal $\mathrm{Ca}^{2+}$ concentration, where increases in $\left[\mathrm{Ca}^{2+}\right]_{\mathrm{i}}$ shifted the voltage-dependent activation curve of the $\mathrm{C}$ current towards less depolarized levels.

Intracellular and extracellular potassium concentrations initially were set to $\left[\mathrm{K}^{+}\right]_{\mathrm{i}}=140 \mathrm{mmol} / \mathrm{l}$ and $\left[\mathrm{K}^{+}\right]_{\mathrm{o}}=\left[\mathrm{K}^{+}\right]_{\text {rest }}=3.82 \mathrm{mmol} / \mathrm{l}$. Intracellular $\left[\mathrm{K}^{+}\right]$was held constant. Extracellular potassium accumulation was governed by the same differential equation as for calcium accumulation (see CALCIUM CURRENTS AND CALCIUM ACCUMULATION), except that $V_{\text {shell, } i}$ now represents a volume of extracellular space of thickness $d_{\text {shell }}=70 \mathrm{~nm}$ surrounding compartment $i$. The $\mathrm{K}^{+}$ accumulation factor $\phi_{i}=2.0$ was assumed to be the same for all compartments, and the extracellular $\mathrm{K}^{+}$decay time constant was $\tau_{\mathrm{K}}=$ $7 \mathrm{~ms}$. Values for $d_{\text {shell }}$ and $\tau_{\mathrm{K}}$ were taken from Yamada et al. (1989). Given these dynamics, the reversal potential for $\mathrm{K}^{+}$currents was determined by the Nernst equation, $E_{\mathrm{K}}=25.0 \times \ln \left(\left[\mathrm{K}^{+}\right]_{\mathrm{o}} /\left[\mathrm{K}^{+}\right]_{\mathrm{i}}\right)$.

\section{Model of fast-spiking GABAergic interneurons}

A basket-type fast spiking (FS) neocortical aspiny interneuron was implemented by a two-compartment model as depicted in Fig. $1 \mathrm{~A}$ (Kawaguchi 1993, 1995; Kawaguchi and Kubota 1997) [the morphological dimensions of this cell were estimated roughly from data on FS cells in frontal cortex given in Kawaguchi (1995)]. FS interneurons provide most of the inhibition in the neocortex including the PFC (Gabbott et al. 1997; Kawaguchi and Kubota 1997), are involved in working memory (Rao et al. 1999; Wilson et al. 1994), and are the major type of interneuron modulated by DA (Gorelova and Yang 1998; Muly et al. 1998; Sesack et al. 1998; Zhou and Hablitz 1999). Passive membrane properties were as follows: $R_{\mathrm{m}}=100 \mathrm{k} \Omega-\mathrm{cm}^{2}$, $C_{\mathrm{m}}=1.0 \mu \mathrm{F} / \mathrm{cm}^{2}, R_{\mathrm{i}}=150 \Omega$-cm, and $E_{\text {leak }}=-68 \mathrm{mV}$ (the behavior of the interneurons in the network was largely insensitive to the exact values of these parameters). $\mathrm{K}^{+}$accumulation dynamics were the same as for the pyramidal cells. The fast $\mathrm{Na}^{+}$and $\mathrm{K}^{+} \mathrm{DR}$ channels included in the somatic and dendritic compartment (Table 1) were sufficient to reproduce the fast-spiking, nonadapting behavior and the strong, brief afterhyperpolarizations after each spike exhibited by FS basket-type cells (Kawaguchi 1993, 1995; Kawaguchi and Kubota 1997). The kinetics of these channels (taken from Lytton and Sejnowski 1991) differed from those of the pyramidal neuron to reproduce the much shorter spike duration in interneurons compared with pyramidal cells (Kawaguchi 1993, 1995; Rao et al. 1999; Wilson et al. 1994) and the faster recovery from $\mathrm{Na}^{+}$channel inactivation (Martina and Jonas 1997a), allowing higher spike firing rates (Table 2).

\section{Network architecture and synaptic currents}

Because little is known about the detailed connectivity of neurons within the PFC and the associated synaptic strengths, we intentionally kept the network model as general and as simple as possible (Fig. 1). A total of 20 deep layer pyramidal cells and 10 GABAergic interneurons were simulated. (Test simulations with larger networks suggested that network size is not a crucial factor for the questions addressed in the present paper.) All pyramidal cells and GABAergic interneurons were fully connected (but see following text). Extensive lateral connections between layer $\mathrm{V}$ pyramidal cells (ranging up to millimeters) in the PFC have been demonstrated by Levitt et al. (1993) and Kritzer and Goldman-Rakic (1995). According to Lübke et al. (1996) and Markram et al. (1997a), these connections between deep layer pyramidal cells involve about four to eight synaptic contacts distributed mainly on the proximal dendritic tree. Thus pyramidal cells in the 
present model were connected reciprocally within the proximal dendritic region; that is, synapses were placed both on the basal and proximal apical dendritic compartment (Fig. 1A). Pyramidal-toGABAergic cell synapses were placed on the dendritic compartments of the interneurons. Inhibitory feedback connections from interneurons to pyramidal cells consisted of $\mathrm{GABA}_{\mathrm{A}}$-like synapses on the somata of pyramidal cells where most inhibitory synapses converge (Douglas and Martin 1990; Thomson and Deuchars 1997). Direct reciprocal interactions between pyramidal cells and FS interneurons are suggested both by in vitro data (Tarczy-Hornoch et al. 1998; Thomson and Deuchars 1997) and by the observation of correlated firing of pyramidal cells and interneurons in the PFC in vivo during working-memory tasks (Constantinidis et al. 1999; Rao et al. 1999). GABAergic interneurons also were interconnected reciprocally by $\mathrm{GABA}_{\mathrm{A}}$-like conductances on their somata. All axonal transmission delays varied in the range of 2-4 ms.

Both pyramidal-to-pyramidal and pyramidal-to-GABAergic cell connections involved both AMPA- and NMDA-like synaptic conductances [for evidence on NMDA-like synaptic conductances on FS interneurons in frontal cortex, see Kawaguchi (1993)]. AMPA-like synaptic currents were modeled by a double exponential function of the form $g_{\text {AMPA,max }} \times\left[\tau_{1} \tau_{2} /\left(\tau_{2}-\tau_{1}\right)\right] \times\left[\exp \left(-t / \tau_{2}\right)-\exp \left(-t / \tau_{1}\right)\right]$ with time constants $\tau_{1}=0.55 \mathrm{~ms}$ and $\tau_{2}=2.2 \mathrm{~ms}$. NMDA-like synaptic currents were modeled as in Mel (1993) by the product of a voltage-dependent gate $s=1.50265 \times\left[1+0.33 \exp \left(-0.06 V_{\mathrm{m}}\right)\right]^{-1}$ with $\tau_{\mathrm{s}}=0.1 \mathrm{~ms}$ (implementing the voltage-dependent $\mathrm{Mg}^{2+}$ block) and a double exponential with time constants $\tau_{1}=10.6 \mathrm{~ms}$ and $\tau_{2}=$ $285.0 \mathrm{~ms}$. Time constants for the AMPA and NMDA currents were taken directly from a study of glutamate receptor channels by Spruston et al. (1995a). The voltage dependency of the NMDA current as given by the $s$-gate in the preceding text also matched the one measured by Spruston et al. (1995a; see their Fig. 4F). Furthermore the relative contributions of AMPA- and NMDA-like currents to excitatory postsynaptic currents (EPSCs; i.e., the ratio $g_{\text {AMPA,max }}$ : $g_{\text {NMDA,max }}$ ) were matched to data from Spruston et al. (1995a). In the absence of more specific knowledge, $g_{\text {AMPA,max }}$ and $g_{\text {NMDA,max }}$ for pyramidal cells and interneurons were assumed to be of equal strength $\left(g_{\text {AMPA,max }}=15.1392 \mathrm{nS}, g_{\text {NMDA, } \max }=0.0912 \mathrm{nS}\right.$, for the baseline configuration, see following text). These conductances were set high enough to allow in concert with spontaneous synaptic inputs (see following text) the maintenance of recurrent activity in the small network for some time similar to that observed in PFC neurons during delayed reaction-type tasks (Funahashi and Kubota 1994; Fuster 1989; Goldman-Rakic 1995). Synaptic reversal potentials were set to $E_{\mathrm{AMPA}}=E_{\mathrm{NMDA}}=0 \mathrm{mV}$ (Angulo et al. 1997; Seamans et al. 1997; Spruston et al. 1995a). GABA A $^{-l i k e}$ currents were modeled by alphafunctions of the form $g_{\mathrm{GABAA} \text {, max }} \times t / \tau_{\mathrm{GABAA}} \times \exp \left(-t / \tau_{\mathrm{GABAA}}+\right.$ 1) with $\tau_{\mathrm{GABAA}}=1.5 \mathrm{~ms}$ and $g_{\mathrm{GABAA} \max }=8.4 \mathrm{nS}$, yielding fast inhibitory postsynaptic potentials as found in neocortical pyramidal cells (Thomson and Deuchars 1997). The reversal potential was $E_{\mathrm{GABAA}}=-75 \mathrm{mV}$ (Ling and Benardo 1998; Thomson et al. 1996).

Stimulus- and/or response-specific delay activity and "opponent memory fields" have been observed in the PFC during workingmemory tasks (Funahashi et al. 1989; Goldman-Rakic 1995, 1996; Quintana et al. 1988; Rainer et al. 1998a; Rao et al. 1997). Thus for example, in the oculomotor delayed response task (Funahashi et al. 1989; Goldman-Rakic 1995, 1996), neurons in the PFC show enhanced firing for a preferred target direction but suppressed firing for targets opposite to the preferred direction. To produce stimulus/ response-specific activity patterns in the small model network used here, two partly overlapping subsets of 10 neurons each (Fig. 1B) were connected by high synaptic weights $\left(g_{\max }\right.$ values as given in the preceding text) within each group and by low synaptic weights $(10 \%$ of the $g_{\max }$ values given in the preceding text) between neurons not belonging to the same cell assembly. These two subsets were meant to represent two different stimuli or motor plans encoded by the synaptic connections of the network (for the present purposes the precise nature of the information encoded in the delay activity is not relevant). Formation of such cell assemblies as originally proposed by Hebb (1949) is suggested by Hebb-like long-term synaptic plasticity mechanisms in the cortex (Levy and Steward 1983; Markram et al. 1997) and is supported by recent multiple-electrode recordings from the PFC (Brody et al. 1999; Constantinidis et al. 1999). Specific activity patterns were evoked by stimulating one of the stored cell assemblies via afferent synapses (see following text) or current injections.

To achieve low spontaneous firing rates in the network as observed in vivo in the PFC (Fuster 1989; Fuster et al. 1985; Rosenkilde et al. 1981), random background synaptic activity was delivered to all pyramidal and GABAergic cells, generated according to Poisson processes convolved with the excitatory (AMPA and NMDA) or inhibitory $\left(\mathrm{GABA}_{\mathrm{A}}\right)$ synaptic conductance changes defined in the preceding text. Background excitatory synaptic inputs were placed on all dendritic compartments of pyramidal cells and interneurons, whereas inhibitory inputs were limited to the proximal stems and somata where pyramidal cells receive most of their inhibitory input (Douglas and Martin 1990; Thomson and Deuchars 1997; Thomson et al. 1996). These inputs mimicked synaptic connections from other neurons within the PFC as well as afferent connections from other cortical or subcortical areas. In low-activity states, the network was driven mainly by this random background activity, which accounted for $>90 \%$ of the total synaptic current in pyramidal cells. In contrast, in high-activity states, the network was dominated by recurrent synaptic activity and the relative contribution of background synaptic inputs was $\sim 50 \%$. The strength and number of background synaptic inputs furthermore were adjusted to approximately produce membrane voltage fluctuations as observed in vivo (Destexhe and Paré 1999; Paré et al. 1998).

\section{Specific afferent network inputs}

The main question of the present study was how DA might affect the robustness of delay (sustained) activity in PFC circuits with respect to distracting input. A distracting input could be any environmental or internally generated stimulus that is incompatible with (or irrelevant to) the current behavioral goal and that tends to evoke a specific representation (activity pattern) in the PFC networks. It thereby interferes (or competes) with the current prefrontal delay activity pattern that encodes information related to the present behavioral goal (Miller et al. 1996; Quintana et al. 1988; Rainer at al. 1999). In delayed-reaction tasks, interfering stimuli have been introduced as part of the experimental design (Fuster 1973; Miller et al. 1996).

Distracting input might arise from many different anatomic sources, involving inputs to the PFC from subcortical (e.g., thalamic), sensory neocortical, or even other prefrontal areas (Fuster 1989; Fuster et al. 1985; Goldman-Rakic 1988; Pandya and Yeterian 1990). Depending on the site of origin, association and transcallosal fiber connections target mainly layers I, III, and V, layers I, IV, and VI, or all layers in the prefrontal cortices (Goldman-Rakic 1988; Isseroff et al. 1984; Melchitzky et al. 1998; Pucak et al. 1996). Hippocampal inputs predominantly contact layers I and V (Swanson 1981). Thalamic inputs distribute mainly throughout layers I, III, and V-VI (Berendse and Groenewegen 1991; Kuroda et al. 1993, 1996) where they contact the dendrites of layer V-VI pyramidal cells (Kuroda et al. 1993). Thus distracting inputs might basically affect all dendritic compartments of deep layer pyramidal cells in the PFC, probably exerting their strongest impact in the proximal basal and apical dendrite region. Hence, in addition to nonspecific background inputs (see preceding text) to all compartments, afferent excitatory (NMDA and AMPA) synapses that specifically target one of the stored cell assemblies were placed on the proximal basal and apical dendrite compartments of the model cells (placing them in addition on the distal model dendrites did not change the results).

To probe stability of PFC representations and to vary the strength of an afferent stimulus, the afferent stimulation frequency rather than 
the synaptic conductance strength was varied because the subjective importance and behavioral relevance of stimuli in prefrontal areas is correlated with firing frequency (Tremblay and Schultz 1999; Watanabe 1996). The synaptic (AMPA- and NMDA-like) conductances of the afferent connections were arbitrarily set five times higher than those of the recurrent synapses. This choice yielded a physiologically reasonable range of afferent stimulation frequencies (i.e., $F_{\text {crit }}$ values, see RESULTS) and allowed sufficient discrimination between conditions.

\section{Dopaminergic modulation}

DA has physiological effects that might vary between different brain regions [for example, DA has effects on NMDA currents in the hippocampal CA1 region (Hsu 1996; Otmakhova and Lisman 1999) opposite from those observed in the PFC and striatum (see following text)]. Hence only effects of DA reported for PFC neurons were used in the present study. We also focused on D1-mediated effects because D1 receptors are much more abundant in the PFC than D2 receptors (Joyce et al. 1993; Lidow et al. 1991) and, more importantly, both working-memory performance as well as delay-activity recorded in vivo in behaving animals is susceptible mainly or exclusively to D1 but not D2 receptor agonists and antagonists (Arnsten et al. 1994; Müller et al. 1998; Sawaguchi and Goldman-Rakic 1994; Sawaguchi et al. 1988, 1990b; Seamans et al. 1998; Williams and Goldman-Rakic 1995; Zahrt et al. 1997). Hence, the short-lasting D2 effects (Godbout et al. 1991; Gulledge and Jaffe 1998; Pirot et al. 1992) may subserve other functions not directly related to holding representations in working memory (see also Durstewitz et al. 1999a). Both deep layer pyramidal cells (Berger et al. 1990; Bergson et al. 1995; Smiley et al. 1994; Yang and Seamans 1996) and FS interneurons (Gorelova and Yang 1998; Muly et al. 1998) in the PFC are equipped with D1 receptors.

DA-induced parameter shifts in the model were varied systematically over some range (see RESULTS) but for some simulations, "baseline" (0\% DA shift) and "high DA" (100\% DA shift) standard configurations were defined as in Tables 1 and 2 and as described below. The high-DA configuration is based on the average shifts in DAdependent parameters observed in vitro (Gorelova and Yang 1997; Seamans et al. 1999; Yang and Seamans 1996; Yang et al. 1997). The following effects of DA on intrinsic ionic and synaptic currents were implemented (see Tables 1 and 2):

1) DA shifts the activation threshold of the persistent $\mathrm{Na}^{+}$current toward more hyperpolarized potentials and slows the inactivation process of this current (Gorelova and Yang 1997; Seamans et al. 1999; Yang and Seamans 1996) (Table 2). This likely contributes to the DA-induced increase in firing rate and reduced adaptation as observed in vitro (Cepeda et al. 1992; Seamans et al. 1999; Shi et al. 1997; Yang and Seamans 1996) and in vivo (Sawaguchi et al. 1988, 1990a,b) in prefrontal pyramidal cells.

2) DA reduces a slowly inactivating $\mathrm{K}^{+}$current in PFC pyramidal cells (Yang and Seamans 1996), as is the case in striatal neurons (Nisenbaum et al. 1998). This was modeled as a reduction in $g_{\mathrm{KS} \text {, max }}$ (Table 1).

3) DA reduces the half-width and amplitude of isolated dendritic $\mathrm{Ca}^{2+}$ spikes (Yang and Seamans 1996). The data of Yang and Seamans (1996) made it likely that this reduction is due to a diminishing effect of DA on a HVA Ca ${ }^{2+}$ current located more in the distal dendrites and thus probably of the $\mathrm{N}$ type, which reaches a local maximum in the distal dendrites of pyramidal cells (Westenbroek et al. 1992; Yuste et al. 1994). A reduction of N-type HVA Ca ${ }^{2+}$ currents by DA has been shown more directly in striatal neurons (Surmeier et al. 1995), in isolated dorsal root ganglia sensory neurons (Formenti et al. 1998), and recently in PFC neurons by Yang et al. (1998). As L- and N-type HVA $\mathrm{Ca}^{2+}$ channels for simplicity were collapsed into a single description in the present model, $\mathrm{HVA} \mathrm{Ca}{ }^{2+}$ conductances in the proximal and distal dendrites were affected dif- ferentially by DA, based on the assumption that DA diminishes the N-type current only. L-type channels are highly clustered within the proximal region and strongly decline toward the distal dendrites (Hell et al. 1993; Westenbroek et al. 1990). In contrast, immunolabeling for $\mathrm{N}$-type channels falls off in the middle of the apical stem of deep layer neurons but rises again within layers II-III (Westenbroek et al. 1992). Thus we assumed that the total HVA $\mathrm{Ca}^{2+}$ current in the distal dendritic compartment was of the $\mathrm{N}$-type, whereas in the proximal region it contributed only $40 \%$ to the total $\mathrm{HVA} \mathrm{Ca}^{2+}$ current as shown in vitro by Brown et al. (1993). DA-induced reductions in the maximum HVA Ca ${ }^{2+}$ conductance $\left(g_{\text {HVA,max }}\right)$ were implemented accordingly (Table 1).

4) Recent evidence shows that DA via the D1 receptor enhances NMDA-like synaptic currents in the PFC (Kita et al. 1999; Moore et al. 1998; Seamans et al. 1999; Zheng et al. 1999), as in striatal neurons (reviewed in Cepeda and Levine 1998; Cepeda et al. 1993; Levine et al. 1996) and as shown earlier in slices from human frontal neocortex (Cepeda et al. 1992). In the high DA configuration, this was modeled by an increase of $40 \%$ in $g_{\text {NMDA,max }}$ (Seamans et al. 1999).

5) In contrast to NMDA-like synaptic currents, non-NMDA or AMPA-like currents seem to be reduced in the frontal neocortex including the PFC (Cepeda et al. 1992; Kita et al. 1999; Law-Tho et al. 1994), as in the striatum (Cepeda et al. 1993). However, this reduction may only be slight in the PFC (Seamans et al. 1999). Nevertheless we investigated the effect of a reduction in AMPA currents as possibly induced by DA by decreasing $g_{\text {AMPA, max }}$ by $20 \%$ in the high DA configuration.

The overall effect of the combined DA-induced changes in AMPA and NMDA currents was to reduce the excitatory postsynaptic potential (EPSP) amplitude but prolong the duration as suggested by in vitro experiments (Cepeda et al. 1992; Kita et al. 1999; Law-Tho et al. 1994; Seamans, unpublished observations).

6) The DA-induced enhancement of $\mathrm{GABA}_{\mathrm{A}}$-like synaptic currents in the PFC (Penit-Soria et al. 1987; Pirot et al. 1992; Rétaux et al. 1991; Seamans et al. 1999; Yang et al. 1997; Zhou and Hablitz 1999) was modeled by an increase in $g_{\text {GABAA,max }}$ of $30 \%$ in the high-DA configuration (Seamans et al. 1999). In addition, DA might enhance spontaneous activity of GABAergic neurons or GABAergic transmitter release in the PFC (Rétaux et al. 1991; Yang et al. 1997; Zhou and Hablitz 1999). This effect was accounted for by increasing the spontaneous background firing rate of GABAergic inputs by $10 \%$ in the high DA condition.

\section{Computational techniques}

The simulation software was written in $\mathrm{C}++$ and run on Pentium PCs using the LINUX operating system. The system of differential equations was integrated numerically using a semi-implicit extrapolation method as described in Press et al. (1992, Ch. 16.6) with an adaptive time step procedure. The (local truncation) error criterion was set to $10^{-4}$, and the minimum time step was limited to $0.1 \mu \mathrm{s}$. To produce random background activity, a (uniform) random-number generator based on data encryption methods as described in Press et al. (1992, Ch. 7.5) was used because it has much better statistical properties than the $\mathrm{C}++$ standard library "rand" function (see Press et al. 1992). A NEURON implementation of the pyramidal cell model is available under ftp://ftp.cnl.salk.edu/pub/dd/pcell.

\section{RES ULTS}

The first two sections serve to illustrate that the model as devised in the METHODS can reproduce basic electrophysiological features of PFC neurons recorded in vitro and in vivo. The main part of the RESULTS then will examine how DA-induced parameter variations affect network states indicated by these 
electrophysiological features and which functional implications for working memory this might have.

\section{Reproduction of the firing pattern of PFC IB pyramidal cells}

The passive properties of the model neuron matched the average $V_{\text {rest }}, R_{\mathrm{IN}}$, and $\tau_{\mathrm{m}}$ of prefrontal IB cells recorded in vitro (see METHODS). In addition, the single pyramidal cell model reproduced the basic properties of spiking behavior of these neurons (Fig. 2A). Current injections into the model cell soma elicited a spike doublet followed by a train of action potentials with adaptation properties similar to those of IB neurons recorded in vitro. With the dopaminergic modulation of intrinsic ion channels in place (high-DA condition; see Tables 1 and 2), the spike frequency of the cell increased almost threefold to the same somatic current

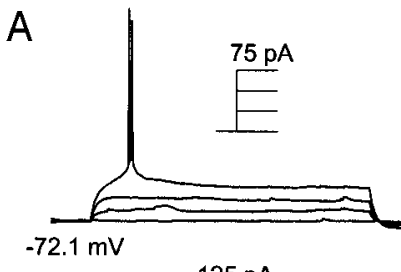

$125 \mathrm{pA}$

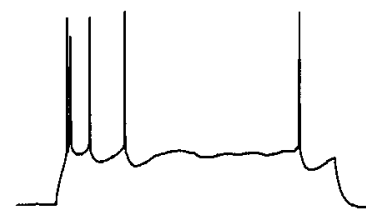

$100 \mathrm{pA}$

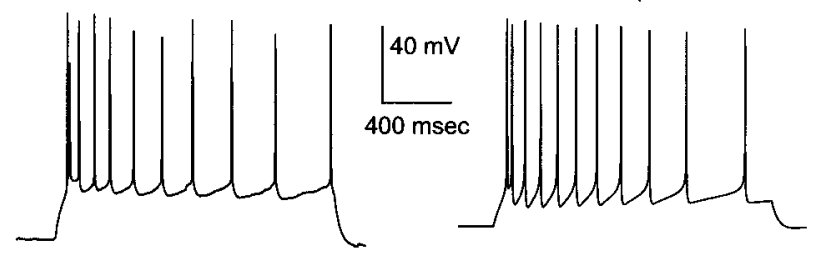

$125 \mathrm{pA}$

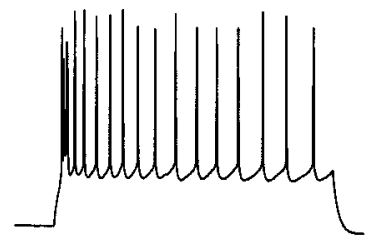

B

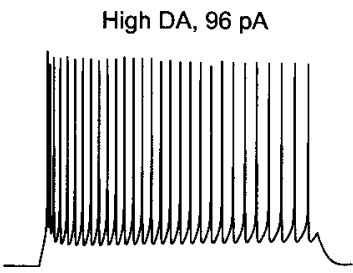

FIG. 2. Comparison of in vitro whole cell recordings and model responses. $A$, left: somatic patch-clamp recordings from an intrinsically bursting (IB) layer $\mathrm{V}$ PFC neuron (2nd trace is from a different neuron than the other 3) while different somatic current steps were applied. Right: responses of the model pyramidal cell to similar current steps. $B$ : implementing the dopaminergic modulation of intrinsic currents yields an about threefold increase in the spike frequency of the model neuron in response to the same current step as used in the 3 rd row of $A$ step (compare Fig. 2, $B$ with $3 r d$ row in $A$ ), as reported for PFC pyramidal cells recorded in vitro after bath application of DA (Yang and Seamans 1996).

\section{Basic network properties}

Figures 3 and 4 illustrate that neurons in the fully connected network model with all internal and external synaptic inputs in place (see METHODS) could reproduce the most salient electrophysiological features of PFC neurons recorded in vivo. Without any additional input or stimulation, neurons in the model network driven by the spontaneous background activity fired at low rates (mean $1.4 \mathrm{~Hz}$ ), comparable with the low spontaneous firing rates of $1-3 \mathrm{~Hz}$ observed for the majority of pyramidal neurons in the primate and rat PFC [Fuster 1973; Fuster et al. 1985; Jung et al. 1998; Rosenkilde et al. (1981) provide a distribution of spontaneous rates; Sawaguchi et al. 1990a]. The spontaneous activity alone, however, was not sufficient to drive the network spontaneously into a state of high, sustained activity, although transient episodes of burst-like activity occasionally appeared in the baseline condition (see Fig. 3A, left). When a high-activity state was evoked by a short-lasting stimulation of one of the stored cell assemblies (either by a current injection or by stimulation of afferent synapses), this activity was sustained at $\sim 17.3 \mathrm{~Hz}$ for prolonged periods of time if the background noise was not too high (Fig. 3A). Thus in a manner similar to delay-active neurons in a working-memory task that hold active a representation of the stimulus or the forthcoming action, high activity was maintained in the network for many seconds after removal of the eliciting stimulus. The rasterplot in Fig. $3 A$ confirms in addition that this activity was stimulus specific, i.e., it was only present in a subset of encoding neurons. GABAergic feedback inhibition ensures that the spread of activity in the network is limited; competing attractors are suppressed and only one pattern can become active at a time.

In general, delay frequencies in the present model network ranged from $\sim 12$ to $36 \mathrm{~Hz}$ (depending on condition, see following text) and were thus well within the range of what has been observed during the delay periods of working-memory tasks (e.g., Di Pellegrino and Wise 1993; Funahashi et al. 1989; Fuster 1973; Miller et al. 1996; Rainer et al. 1998b). Firing frequencies, however, could climb transiently to much higher values, especially during the presentation of a stimulus. The frequency of the interneurons during delay activity ranged from $\sim 45$ to $100 \mathrm{~Hz}$, in agreement with available in vivo data (Wilson et al. 1994). The fact that stimulus-specific, recurrent activity could be maintained in the network at quite low rates $(<20 \mathrm{~Hz})$ is in itself not trivial because of the short axonal propagation and transmission delays (2-4 ms in the present model) and the fast AMPA-kinetics. In addition, selective high activity could be maintained in the presence of considerable noise (see METHODS). These characteristics depended critically on the slow time course and voltage-dependence of NMDA conductances. Finally, in high-activity states, spike trains were highly irregular (Figs. 3, $A$ and $B$, and $4, A$ and $B$ ) with coefficients of variation $\left(C_{\mathrm{v}}\right)$ ranging from 0.5 to 0.8 , as observed in in vivo recordings from neocortical neurons (Bodner et al. 1997; Shadlen and Newsome 1994; Softky and Koch 1993).

In summary, these simulations demonstrate that the network model established here exhibits network states and behavior as observed in the PFC in vivo, thus providing a physiologically plausible starting point to explore the effects of DA-induced 
A Baseline
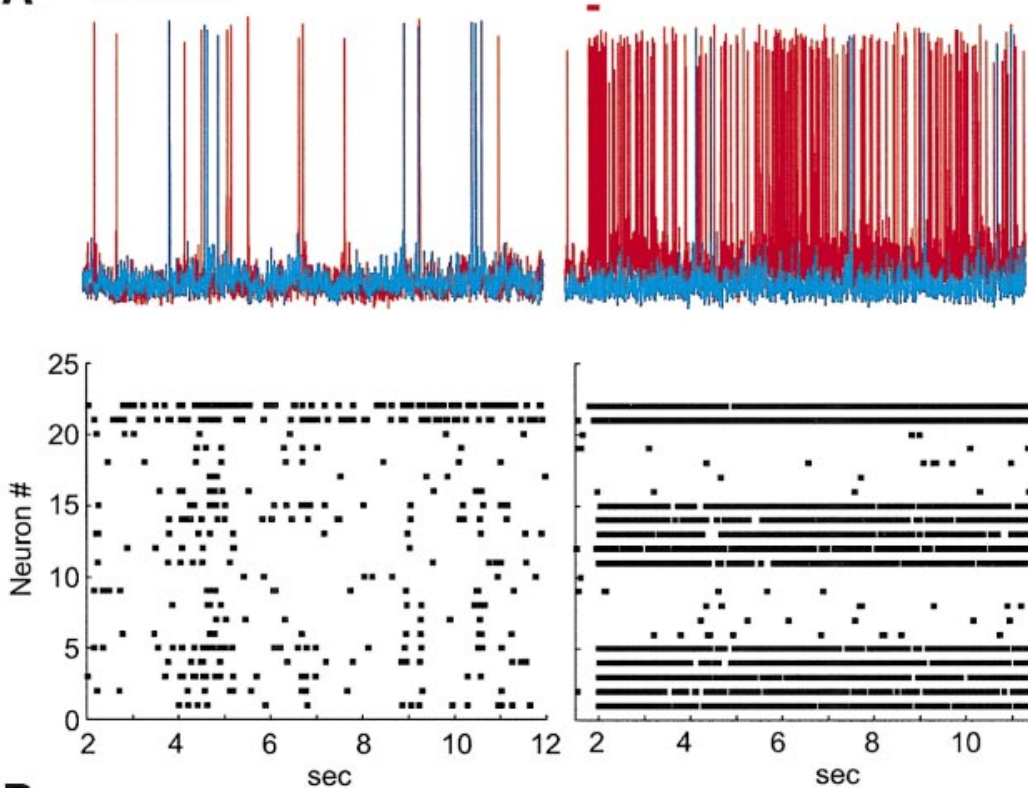

B High DA
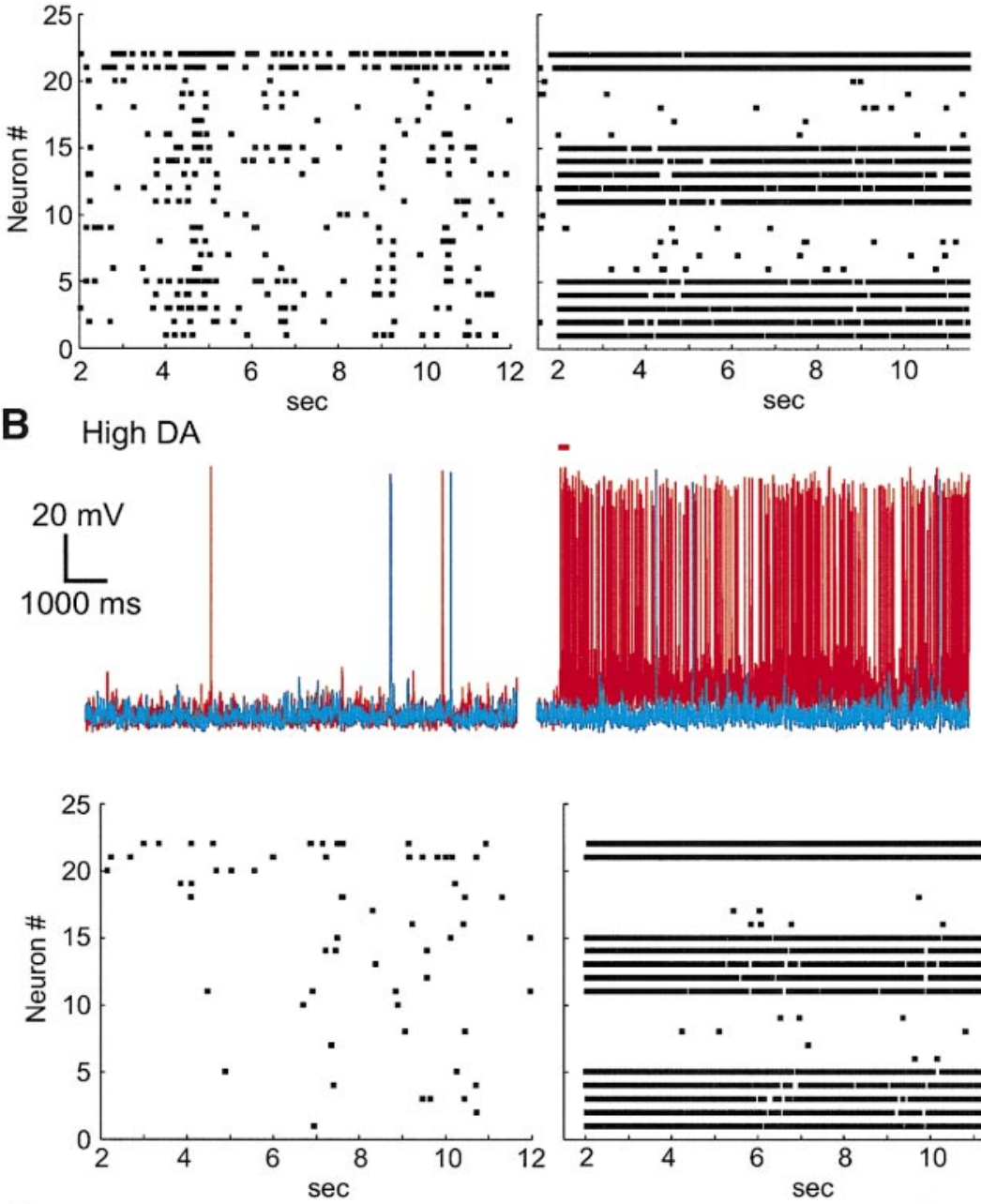

C

Baseline

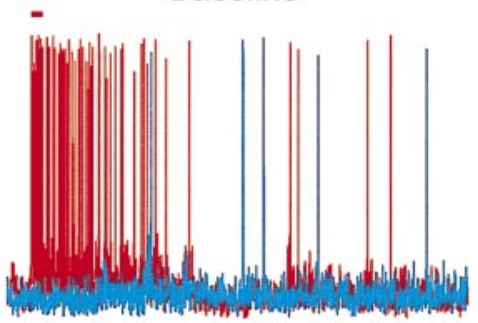

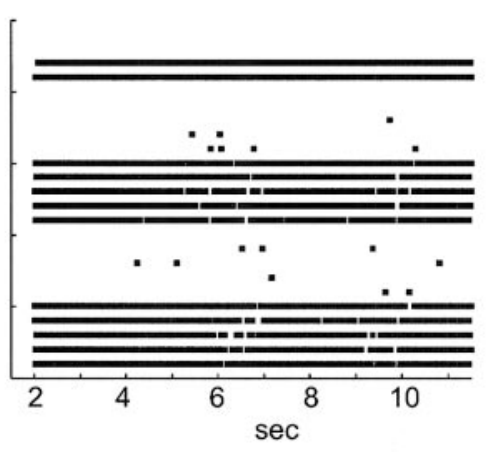

High DA

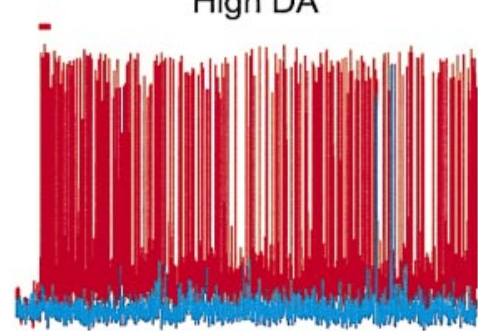

FIG. 3. Dopaminergic modulation of low- and high-activity states in the model network. A: somatic voltage traces (top) of 2 neurons under the baseline condition, 1 of which participates in the target pattern representation (red traces), whereas the other does not (blue traces). A low-activity state of the network driven mainly by the random background activity (left) and a state of high, sustained activity driven mainly by recurrent excitation in one group of neurons (right) are shown. The high-activity state was induced by a short current pulse (red bar) into the target pattern neurons. Bottom: activity of all 20 pyramidal neurons and 2 representative GABAergic interneurons (neurons 21 and 22) as raster-plots (where each point represents a spike in the respective neuron). The raster-plot (right) shows that sustained high activity is specific for target pattern neurons. $B$ : same as in $A$ for the high-dopamine (DA) condition. Note that spontaneous (low) activity was reduced (left), whereas high recurrent activity was enhanced (right) compared with the baseline condition shown in $A$. Differences in the activity states are mirrored by the firing rates of the GABAergic neurons, which are driven by the pyramidal cells. $C$ : if background noise is increased, a high-activity state in the baseline condition (left) decays much earlier than in the high-DA condition (right). parameter variations on these network states and their functional implications.

\section{Differential dopaminergic modulation of activity states}

In the present network, a simulated rise in DA level by shifting intrinsic and synaptic ion channel parameters into the
high-DA configuration led to suppression of the low firing state (mean $0.3 \mathrm{~Hz}$; Fig. 3B). This suppression was caused by the relative dominance of the inhibitory over the excitatory actions of DA in the low-activity state (i.e., by the increased GABAergic inhibition and the reduced N-type $\mathrm{Ca}^{2+}$ and AMPA currents). In contrast, when a high-activity state was elicited by a 
A

$$
F_{\text {stm }}=10 \mathrm{~Hz} \quad \text { Baseline } \quad F_{\text {stm }}=20 \mathrm{~Hz}
$$
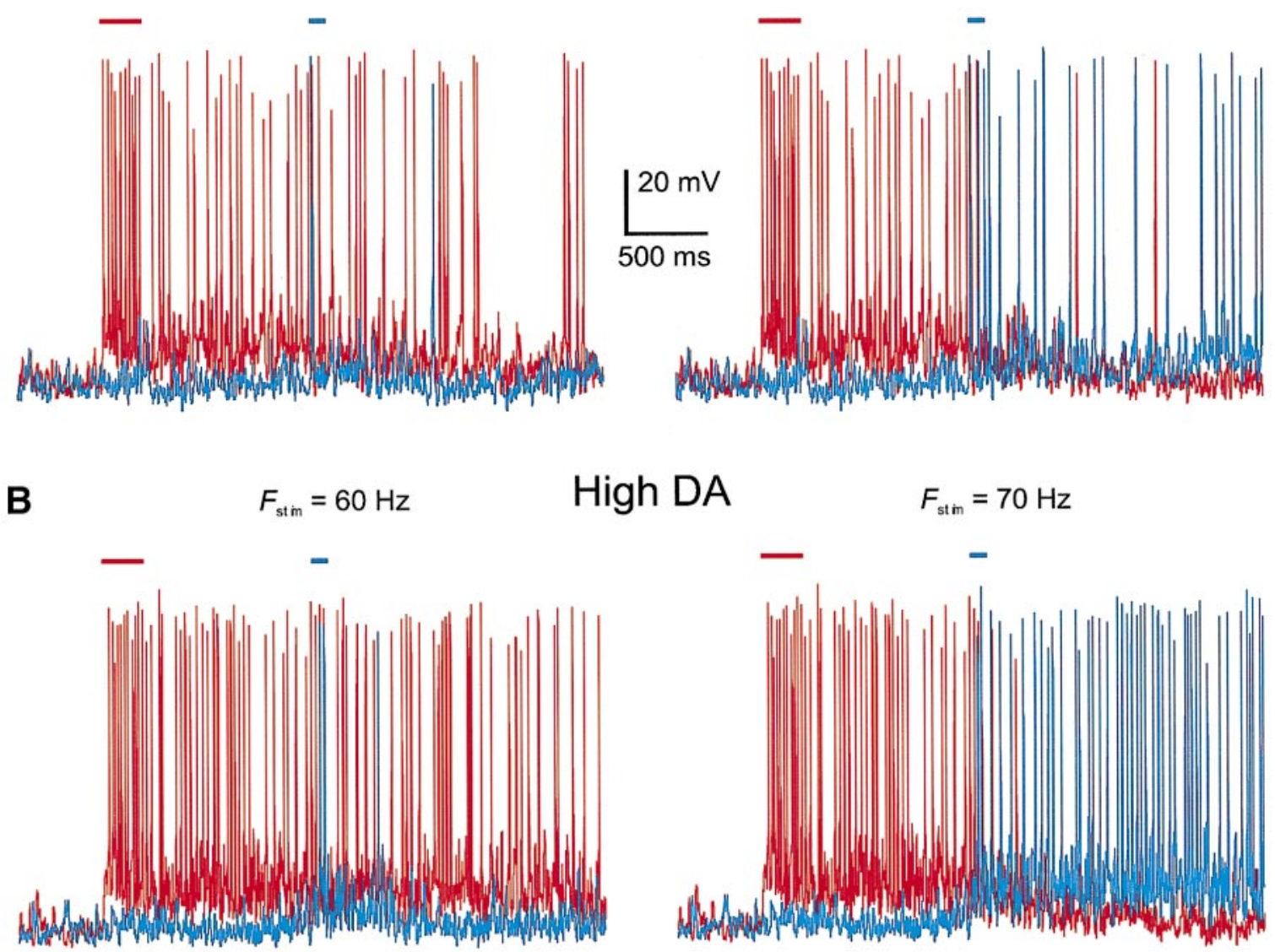

High DA

$F_{\text {stim }}=70 \mathrm{~Hz}$
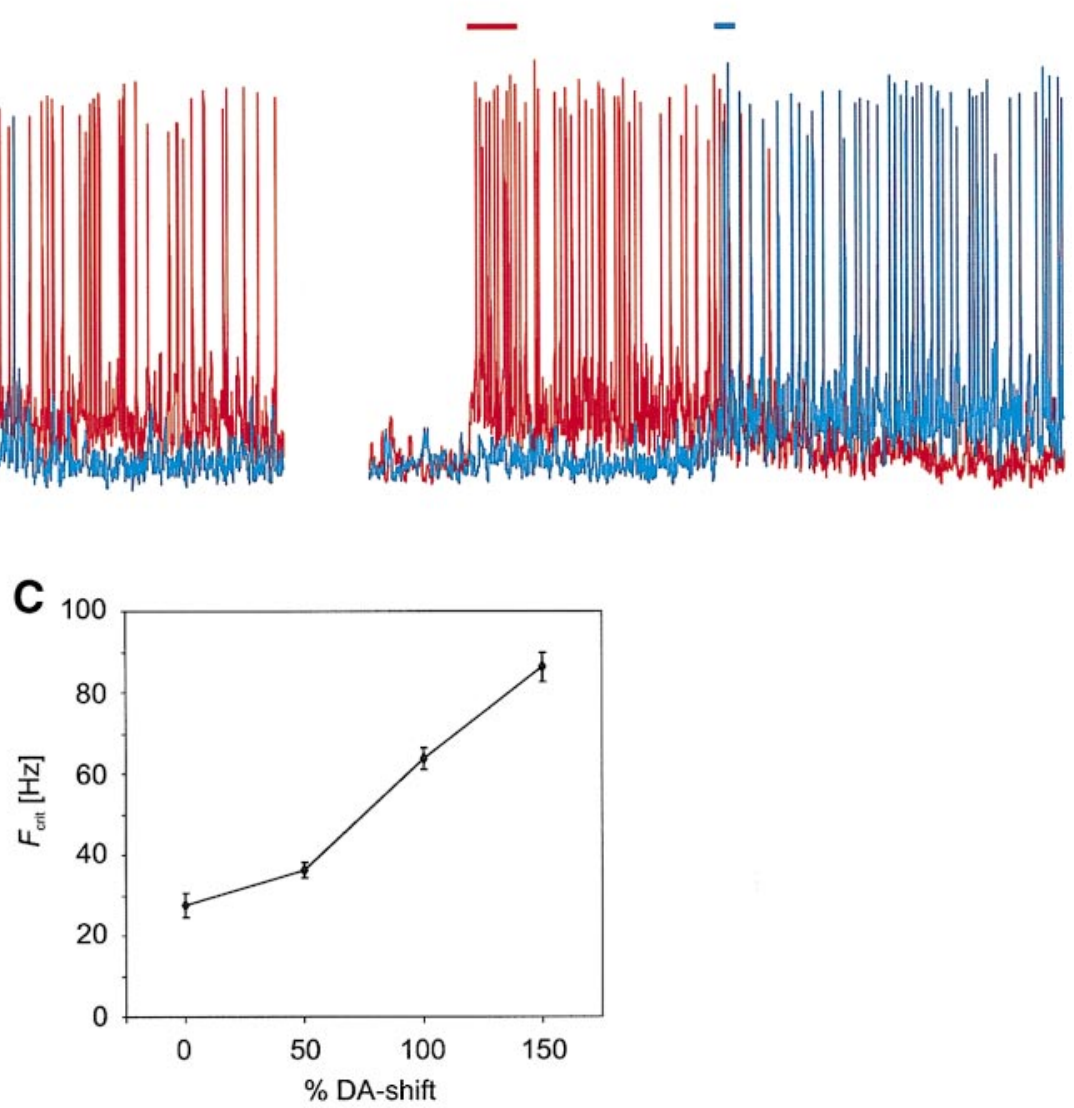

FIG. 4. Simulated DA modulation increases stability of target pattern representations. A: example membrane potential traces from a neuron participating only in the target pattern (red traces) and 1 participating only in the distractor pattern (blue traces) under the baseline condition. Target pattern activity was evoked by a 250 -ms current injection (red bar). A second later, distractor pattern neurons were synaptically stimulated for $100 \mathrm{~ms}$ (blue bar). At low afferent stimulation frequencies $\left(F_{\text {stim }}\right)$, the target pattern stays stable and is maintained for at least another second after offset of distractor pattern stimulation (left). With $F_{\text {stim }}$ increased to 20 $\mathrm{Hz}$, the target pattern collapses and is replaced by the distractor pattern (right). B: same as under $A$ for the high-DA condition. Note that much higher stimulation frequencies were required to disrupt target pattern activity than under the baseline condition shown in $A$. $C$ : stability of the target pattern, as measured by the minimal afferent stimulation frequency $\left(F_{\text {crit }}\right)$ required to disrupt the target pattern, as a function of the percentage of the shift in DA-modulated parameters relative to the differences between the baseline and the high DA configuration (see text). Error bars indicate SE.

transient stimulus, DA enhanced this sustained activity, and the average firing frequency rose from $\sim 17.3 \mathrm{~Hz}$ in the baseline condition to $\sim 25.8 \mathrm{~Hz}$ in the high-DA condition. Conversely the activity of neurons not participating in the representation of the evoked pattern (the "background neurons") was more strongly suppressed in the high-activity state in the high-DA 
condition compared with the baseline condition (compare raster plots in Fig. 3, $A$ and $B$ ). In the high-activity state, the excitatory actions of DA dominated its inhibitory actions. Thus the net effects of DA on neural firing depended on the initial activity state of the network. In the high-DA condition, sustained "delay activity" was also more robust with respect to the random fluctuations in background activity: If the impact of noise on network activity was increased, sustained activity in the baseline condition had the tendency to break down much earlier than in the high-DA condition (Fig. 3C).

The switch from a predominantly "inhibitory" to a predominantly "excitatory" action of DA from low to high levels of activity stems mainly from the highly increased contribution of the slow NMDA currents in the high-activity state: During high activity, DA causes a large boost in long-lasting recurrent excitation, further amplified by the increase in firing frequency by the enhancement of $I_{\mathrm{NaP}}$. In addition, the fact that the persistent $\mathrm{Na}^{+}$and the NMDA but not the $\mathrm{GABA}_{\mathrm{A}}$ and AMPA conductances are voltage-dependent means that the former two but not the latter increase at higher levels of activity. Thus the relative impact of the $I_{\mathrm{NaP}}$ and NMDA conductances grows with network activity.

The simulations reported above highlight a functionally important principle, namely that DA's effects depend on the activity state of a cell assembly such that foreground in relation to background activity is enhanced. It is important to note that the differential modulation of low- and high-activity states by DA is an intrinsic property of the activity/voltage and time dependencies of the particular conductances affected by DA and as such does not depend on the particular parameter configuration. Thus even for parameters for which the lowactivity state also was amplified by DA, there was always a much larger enhancement of the high-activity state, which in turn led to increased GABAergic feedback suppressing the background neurons. The differential DA-induced enhancement of sustained activity in the network is also consistent with the enhancements of task-related activity demonstrated in vivo during working-memory tasks (Sawaguchi et al. 1988, 1990a,b).

\section{Effects of DA on the stability of active patterns}

In the following sections, the possible functional implications of the differential modulation and the DA-induced parameter changes will be examined. Sustained (delay) activity of neurons in the PFC selectively encodes stimulus or motor information relevant to the current behavioral goal (Asaad et al. 1998; Di Pellegrino and Wise 1993; Funahashi et al. 1989; Fuster 1989; Quintana and Fuster 1999; Rainer et al. 1998a,b, 1999; Rao et al. 1997; Rosenkilde et al. 1981). Both disrupted delay activity as well as delay activity coding for the wrong stimulus or response are correlated with subsequent behavioral errors (Funahashi et al. 1989; Fuster 1973; Quintana et al. 1988). In the following, the activity pattern that has to be maintained during the delay for successful goal achievement or behavioral performance will be referred to as the "target pattern." A stimulus that is not relevant to the present task or behavioral goal and hence interferes with the target pattern will be referred to in the following as the "distractor pattern." Durstewitz et al. (1999a) showed how the PFC might detect patterns that are important to the present goal (and thus differ- entiate them from distractor patterns) via "match enhancement neurons" (e.g., Miller et al. 1996), and how these neurons could generate a signal that via a cortico-striatonigral feedback loop finally terminates target pattern activity again on achieving the goal.

To explore the idea that DA increases the robustness of target pattern representations (encoded by delay-active neurons) with respect to distracting patterns, parameters modulated by DA were linearly varied, either in combination or independently, within a physiologically reasonable range, using the difference between the baseline and the high-DA configuration as a standard. Thus the differences between the baseline and the high-DA configuration as given in METHODS and in Tables 1 and 2 were defined arbitrarily as a $100 \%$ shift in DA-dependent parameters, and other conditions were expressed relative to these standard difference values (i.e., normalized to them). For each of these different "DA levels" (parameter shifts), the minimal frequency of an afferent synaptic stimulation of the distractor pattern neurons that was sufficient to disrupt the target pattern and evoke a transition to the distractor pattern was determined. This is illustrated in Fig. $4, A$ and $B$, for the baseline and the high-DA situation, respectively: First a target pattern was evoked by a 250 -ms current injection $(0.45 \mathrm{nA})$ into the somata of the neurons coding for that pattern. (Synaptic stimulation yielded the same results, but current injection was used instead to ensure that at the time when the interfering pattern arrived, target pattern activity was driven only by recurrent network inputs and was no longer aided by afferent inputs.) Next, $1 \mathrm{~s}$ after the target pattern stimulation was shut off, afferent synapses to the distractor pattern were stimulated for $100 \mathrm{~ms}$. For low-frequency stimulation of the distractor pattern, the target pattern remained stable, but at a certain stimulation frequency $\left(F_{\text {crit }}\right)$, it broke down (due to the increased GABAergic feedback induced by the distractor pattern stimulation), and a transition to a new activity state occurred. At this critical frequency, the current contents of working memory are lost.

As a criterion for stability, target pattern activity had to be maintained at frequencies $>10 \mathrm{~Hz}$ for $\geq 1 \mathrm{~s}$ after offset of the distractor pattern stimulation. $F_{\text {crit }}$ values were determined in steps of $10 \mathrm{~Hz}$ such that each step meant one additional afferent spike within the 100 -ms stimulation period. Hence $F_{\text {crit }}$ also can be read as the number of equally spaced afferent spikes within the stimulation period. In a few cases $(<6 \%)$, stability was not a monotone function of stimulation frequency but could exhibit "jumps" within a narrow critical range. In these cases, $F_{\text {crit }}$ was defined as the first stimulation frequency where disruption of the target pattern occurred. Note from Fig. 4, A and $B$, that even suprathreshold activity in the distractor pattern neurons may not be sufficient to shut down the target pattern and enforce a transition to the distractor pattern unless the distractor pattern neurons gain sufficiently high firing rates.

Highly irregular firing patterns and strong membrane voltage fluctuations are characteristic features of neocortical neurons recorded in vivo (Destexhe and Paré 1999; Paré et al. 1998; Shadlen and Newsome 1994; Softky and Koch 1993) and are prominent in PFC neurons during the delay periods of working-memory tasks (Bodner et al. 1997). Hence we especially were interested in how DA might affect the robustness of active representations in the presence of high noise and high variance of the membrane potentials and interspike intervals. 
Because the random synaptic background activity made a major contribution to the total synaptic current (see METHODS), eight sets of simulations with different synaptic background patterns were run, and $F_{\text {crit }}$ values were averaged across these conditions. This procedure also provided a robustness check because different background patterns produced quite different spiking patterns in the recurrent network, thus demonstrating that our results hold despite high levels of noise and with different firing patterns. The $F_{\text {crit }}$ values reported in the following should be interpreted in relative rather than absolute terms because the absolute values depend on other parameters such as the synaptic strength of the afferent inputs (see METHODS) and the delay times, which were kept fixed for these simulations.

Figure $4 C$ shows that the critical afferent frequency $\left(F_{\text {crit }}\right)$ increased more than threefold across the range of simulated DA levels, i.e., with the magnitude of the changes in the DA-modulated parameters. Hence over a range of physiologically plausible parameters, the dopaminergic modulation leads to an increase in stability of the currently active representation with respect to interfering stimuli.

Additional simulations confirmed that an increase in stability with increasing DA-induced parameter shifts holds under the following conditions: for longer or shorter time intervals (delays) after target pattern onset; with background activity shut off completely (i.e., no noise); stimulation of the distractor pattern by DC injections into the dendrites of the distractor pattern cells; additional stimulation of GABAergic interneurons conjointly with the distractor pattern pyramidal cells (i.e., including a strong feedforward inhibitory component); and no overlap between the target pattern and the distractor pattern (i.e., no shared neurons). In the latter case, an increase in overall stability occurred while the ordinal relationships between different DA levels were preserved, consistent with previous findings (Durstewitz et al. 1999a).

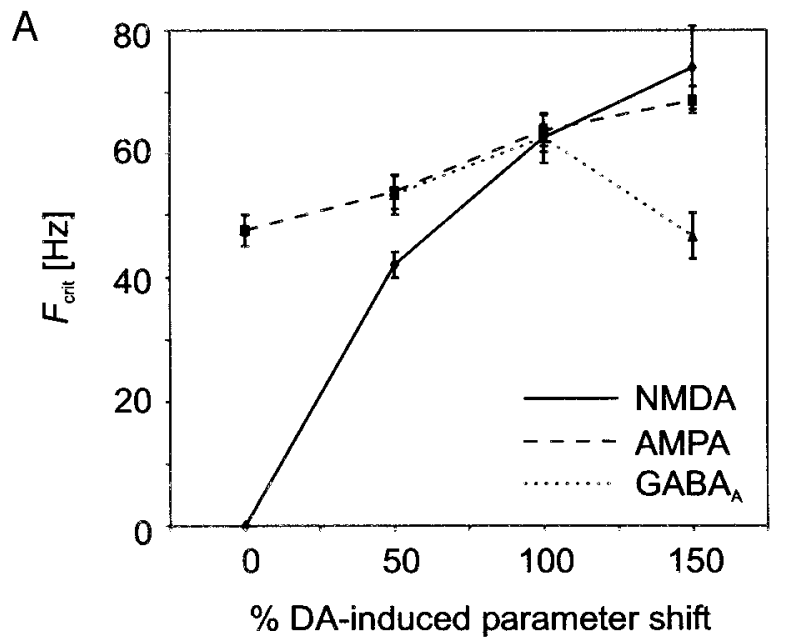

\section{Ionic currents contributing to the DA-induced stabilization}

To assess which of the DA-modulated conductances could contribute to an enhancement of stability, each was varied independently while the other parameters affected by DA were set to the high-DA values given in METHODS. As shown in Fig. 5, $A$ and $B$, the DA-induced alterations in the persistent $\mathrm{Na}^{+}$ conductance, and, somewhat counterintuitively, both, the increase in the NMDA conductance as well as the decrease in the AMPA conductance increased stability of the target pattern over the range of parameters tested. The stability-increasing effects of the DA-induced alterations in these conductances were present in each of the eight different sets of simulations as well as in the control simulations listed above. The enhancement of $I_{\mathrm{NaP}}$ and NMDA conductances might increase stability through several mechanisms. Most importantly, the spike rate of the pyramidal cells increased due to enhanced recurrent excitation and $I_{\mathrm{NaP}}$-mediated amplification of EPSPs (Schwindt and Crill 1995, 1996; Stuart and Sakmann 1995). This in turn elevated the firing rate of the GABAergic interneurons, which receive inputs from the pyramidal cells, resulting in an enhanced GABAergic feedback to the pyramidal cells that is more difficult for any interfering input to overcome. The increased firing of the target pattern neurons also implies that a higher firing rate has to be obtained in the distractor pattern neurons to achieve the same level of NMDA conductance activation as in the target pattern neurons. The slow kinetics and voltage dependence of the NMDA conductance are critical for this effect as evidenced by the fact that a decrease in $g_{\text {AMPA }}$, which is voltage-independent and has a short time course, also enhances stability.

The increased stability with a reduction in $g_{\text {AMPA }}$ may be partly due to the reduction in the afferent excitatory synaptic current to the distractor pattern neurons: When $g_{\text {AMPA }}$ was changed only for the internal recurrent excitatory synapses but not for the external inputs, the increase in stability with a

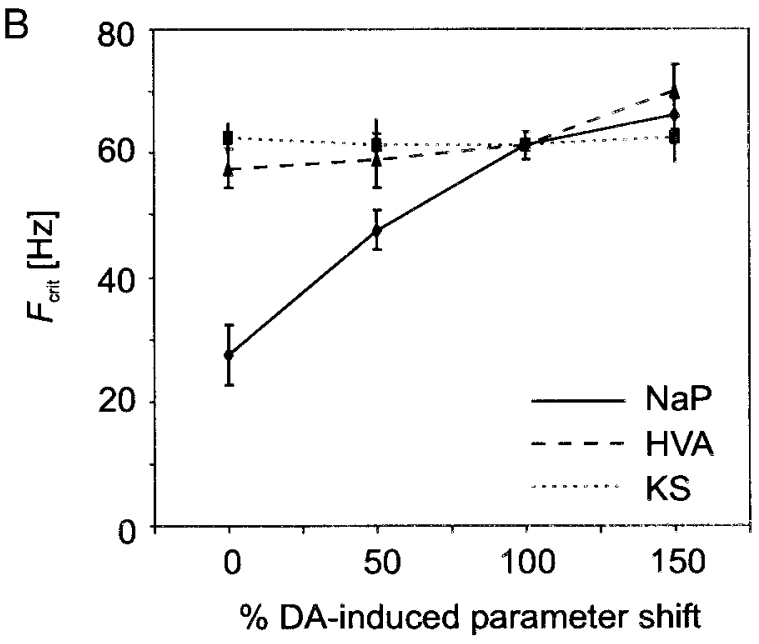

FIG. 5. Stability of target pattern representations as a function of shifts in each of the DA-modulated channel parameters. A:

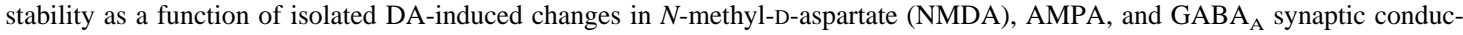
tances. Percentages refer to the magnitude of change relative to the difference between the high-DA and the baseline values (see

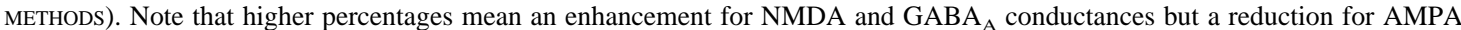
currents. For the $0 \%$ NMDA condition, no delay activity at all was elicited, i.e., there was an immediate cessation of activity after offset of the stimulation. $B$ : stability as a function of isolated DA-induced changes in the persistent $\mathrm{Na}^{+}$current $(\mathrm{NaP})$, the slowly inactivating $\mathrm{K}^{+}$current (KS), and the HVA N-type $\mathrm{Ca}^{2+}$ current (HVA). For each of these parameter variations, all other parameters were fixed in the high-DA configuration (see METHODS and Tables 1 and 2). Error bars indicate SE. 
reduction in $g_{\text {AMPA }}$ became less pronounced or disappeared in two simulations with different random background. Hence both the target and the distractor pattern neurons may suffer about equally from a reduction in recurrent AMPA-mediated excitation, but the distractor pattern neurons suffer in addition from the fact that a reduction in $g_{\text {AMPA }}$ also affects the external inputs to these neurons.

Stability did not increase monotonically with the enhancement of $\mathrm{GABA}_{\mathrm{A}}$ conductances but, in the present set of simulations, peaked at the $100 \%$ condition (Fig. 5A). Hence, whether an increase in $\mathrm{GABA}_{\mathrm{A}}$ conductances enhances or reduces stability might depend on the magnitude of the parameter shift. Besides a possible role in stability, an increase in $\mathrm{GABA}_{\mathrm{A}}$ conductances concurrently with the other DA-induced parameter changes was a necessary prerequisite for proper functioning of the network model. Without an increase in $g_{\text {GABAA }}$ along with the other DA-induced alterations, the network rapidly and almost inevitably pushed itself into one of the high-activity states within the first $2 \mathrm{~s}$ after the network was started, even without an external stimulus (Fig. 6A). (For this reason, it was not possible to obtain a stability estimate for the GABA $0 \%$-condition in Fig. 5A.) Figure $6 B$ quantifies this phenomenon for different DA levels. For a $50 \%$ DA shift in $\mathrm{GABA}_{\mathrm{A}}$ currents, spontaneous jumps were still very likely to occur, but they never happened in any of the simulations run with the 100 and $150 \%$ DA shifts in $g_{\text {GABAA }}$ (Fig. 6B). Thus a major function of the DA-induced increase in GABAergic currents may be to maintain control over the network behavior and to keep the network responsive to the correct stimulus conditions. Self-induced high-activity states also occurred occasionally with the $150 \%$ shifts in $I_{\mathrm{NaP}}$ or $g_{\mathrm{NMDA}}$ alone, emphasizing the need for suppression of this phenomenon at high-DA levels.

A reduction in $g_{\mathrm{HVA}}$ tended to increase stability in the present model (Fig. $5 B$ ). To examine how a reduction in $g_{\text {HVA }}$ might increase stability, trains of sub- or suprathreshold EPSPs of different amplitudes were evoked in single-model neurons, and the change in EPSP amplitude or firing frequency upon $g_{\text {HVA }}$ reduction was assessed. In the subthreshold range and at low firing rates, $I_{\text {HVA }}$ amplified EPSPs in the present model neurons (consistent with findings by Seamans et al. 1997) such that neurons with low firing rates suffered from a reduction in $g_{\text {HVA }}$ (not shown). In contrast, high-frequency firing led to strong $\mathrm{Ca}^{2+}$ accumulation (Helmchen et al. 1996) and consequently to strong activation of $\mathrm{Ca}^{2+}$-dependent $\mathrm{K}^{+}$currents like $I_{\mathrm{C}}$ in the present model. Hence at constantly high firing rates, $g_{\text {HVA }}$ reduction actually could produce a slight increase in firing rate (as supported by data from Schwindt and Crill 1997) (not shown). Thus a $g_{\text {HVA }}$ reduction might differentially affect target pattern and nontarget pattern neurons in the network.

A reduction in $g_{\mathrm{KS}}$ had almost no effect on stability in the present model in the range over which it was varied. It enhanced subthreshold EPSPs and initial responses but increased firing at frequencies $>15 \mathrm{~Hz}$ only slightly. To determine whether this was due to the particular $g_{\mathrm{KS}}$ kinetics or to its comparatively low contribution to the total membrane conductance in the cells modeled here, simulations were run with $g_{\text {KS, max }}$ increased 2.5-fold (compared with the baseline condition). In these simulations, stability decreased remarkably (mean $F_{\text {crit }} \leq 38 \mathrm{~Hz}$ ), indicating that in neurons with an initially quite strong $g_{\mathrm{KS}}$, its reduction indeed could have a profound stabilizing effect.

In conclusion, DA-induced alterations in the persistent $\mathrm{Na}^{+}$, and the NMDA and AMPA synaptic currents monotonically increased stability over the range of parameters tested here. A reduction in $I_{\mathrm{HVA}}$ might have a stabilizing effect by mainly reducing EPSP sizes in background neurons while reducing $\mathrm{Ca}^{2+}$-dependent $\mathrm{K}^{+}$currents in foreground neurons. DA-induced alterations in $\mathrm{GABA}_{\mathrm{A}}$ conductances could prevent spontaneous switches into high-activity states that might otherwise interfere with proper working-memory function.

\section{I S C U S S I O N}

The present paper investigated the possible functional implications of the dopaminergic modulation in the PFC in a
A

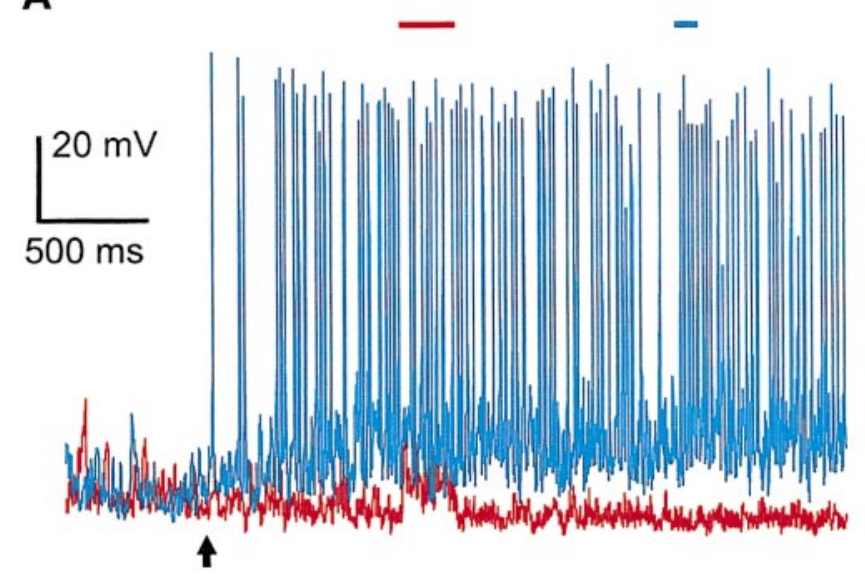

B

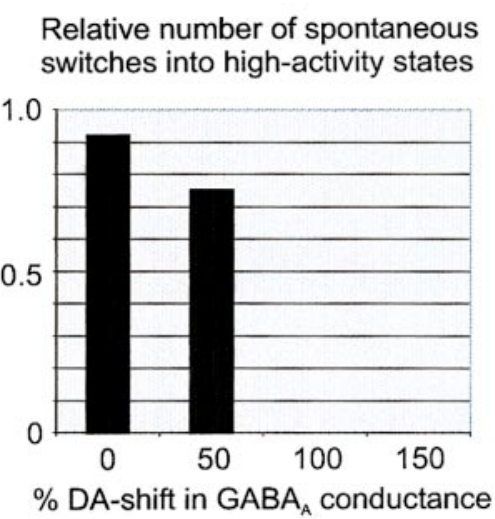

FIG. 6. DA-induced increase in $\mathrm{GABA}_{\mathrm{A}}$ currents is required to control activity states. A: with all other DA-induced parameter

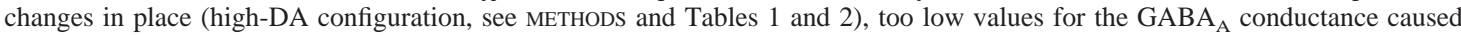
the network to automatically jump into one of the high-activity states without presentation of a stimulus. In the present example, the wrong attractor "popped out" spontaneously (arrow) so that the correct target pattern could not even be induced (red bar) using standard parameters. (For comparison with Fig. 4, the blue bar indicates the time of distractor pattern stimulation.) B: relative frequencies of spontaneous (task-unrelated) jumps into high-activity attractor states within the 1st $2 \mathrm{~s}$ of the free-running network as a function of DA-induced changes in $g_{\mathrm{GABAA}}(n=12)$. 
network of compartmental model neurons. In the model network, DA strongly enhanced task-related high-activity states while suppressing background activity. Through these differential effects, the robustness of delay period activity, which presumably reflects goal-directed processing, with respect to afferent stimuli interfering with the present network state was highly increased. Several ionic conductances might contribute to these differential effects of DA. Most importantly, the DAinduced enhancements of $I_{\mathrm{NaP}}$ and NMDA currents had a much larger impact for highly active neurons embedded in a recurrent network than for neurons in a low state of activity that did not participate in the active pattern. A DA-induced reduction in $\mathrm{N}$-type $\mathrm{Ca}^{2+}$ currents also might enhance stability because it mainly leads to diminished amplification of EPSPs during low activity (Seamans et al. 1997), whereas it mainly causes a reduction in $\mathrm{Ca}^{2+}$-activated $\mathrm{K}^{+}$currents at higher firing frequencies (Schwindt and Crill 1997). Finally, a reduction of AMPA conductances might contribute to stability by diminishing mainly the impact of afferent inputs on nontarget pattern neurons.

In the context of the activity-enhancing effects of DA, the function of the DA-induced enhancement of $\mathrm{GABA}_{\mathrm{A}}$ currents might be to readjust the overall level of network activity so that the network does not automatically get pushed into highactivity states by spontaneous activity. Such spontaneous "popouts" would be detrimental in a working-memory context where specific patterns have to be activated and held active in a task-related manner.

\section{Role of DA in working memory and goal-directed behavior}

Stability of neural activity encoding goal-related information including goal-directed movements is an essential prerequisite of any goal-directed behavior that extends over time. The PFC generally is believed to underlie goal- and memoryguided behavior as well as the temporal organization and planning of behavior (Cohen et al. 1997; Dehaene et al. 1999; Fuster 1989; Goldman-Rakic 1995; Kesner et al. 1994; Koechlin et al. 1999; Milner and Petrides 1984). If the contents of working memory are wiped out by interfering stimuli or response tendencies, goal-directed behavior will fail (Funahashi et al. 1989; Fuster 1973, 1989). Thus PFC circuits should be equipped with neural mechanisms that ensure the stability of delay activity in the presence of interfering stimuli. Miller et al. (1996) have shown that prefrontal neurons indeed can maintain delay-activity even if stimuli intervene between a cue and a matching target stimulus. On the other hand, prefrontal patients and animals, which presumably lack such a mechanism, suffer from an inability to plan and temporally organize their behavior, from a high distractibility, and from failures to inhibit interfering or well-learned response tendencies (Dias et al. 1997; Fuster 1989; Iversen and Mishkin 1970; Kesner et al. 1994; Milner and Petrides 1984; Seamans et al. 1998; Zahrt et al. 1997).

It also has been shown that dopaminergic midbrain neurons become active at the onset of working-memory tasks (Schultz et al. 1993), that DA levels in the PFC increase during working memory (Watanabe et al. 1997), and that optimal stimulation of dopaminergic receptors is essential for proper workingmemory performance in rats (Murphy et al. 1996a,b; Seamans et al. 1998; Zahrt et al. 1997), birds (Durstewitz et al. 1999b;
Güntürkün and Durstewitz 2000), monkeys (Arnsten et al. 1994; Murphy et al. 1996a,b; Sawaguchi and Goldman-Rakic 1994), and humans (Luciana et al. 1998; Müller et al. 1998). In addition, it has been shown in vivo that DA in the PFC specifically increases the firing rate of neurons active during the delay, cue, and response periods of working-memory tasks and that this enhancement is primarily due to D1-receptor stimulation (Sawaguchi et al. 1988, 1990a,b). On the basis of this evidence, it has been proposed that DA in the context of working-memory performance might stabilize neural representations coding for goal-related information, and it has been demonstrated in a network of simple leaky-integrator units that the DA-induced shifts in the parameters of several currents could in principle fulfill this function (Durstewitz et al. 1999a).

The network simulations presented here confirm and extend the findings from the simpler model in several important ways. First, the simpler model investigated previously had the advantage that many effects of DA could be analyzed and understood relatively easily, but it lacked biological detail in many respects. Therefore, to confirm that the effects of DA were not an artifact of the simple model architecture, the present network model used highly realistic PFC compartmental model neurons with Hodgkin-Huxley-like membrane kinetics that could reproduce in vitro whole cell recordings, and it was tuned to exhibit in vivo-like behavior. The present results show that the DA-induced stability of neural representations also obtains in this biologically more realistic model and that the underlying mechanisms observed in the simple model also occurred in the realistic model. In both models, a DA-induced enhancement of $I_{\mathrm{NaP}}$ led to higher activity of the foreground neurons that resulted in stronger inhibition of the background neurons through feedback inhibition. Moreover, a reduction in AMPA currents in both models resulted in higher stability primarily via reduction of the afferent input strength (Durstewitz et al. 1999a).

Second, the previous model did not provide a satisfying explanation for the role of the DA-induced increase in GABAergic currents. The present simulations suggest that the increased GABAergic inhibition might be essential in rescaling the overall level of activity and in keeping the high-activity states of the network under the control of the inputs. Third, the previous model did not differentiate between AMPA and NMDA conductances but collapsed them into a single, shortlasting, voltage-independent excitatory efficiency. Mounting evidence, including recent experiments in our laboratory, suggests that AMPA and NMDA currents are differentially affected by DA in the PFC (Cepeda et al. 1992; Kita et al. 1999; Moore et al. 1998; Seamans et al. 1999; Zheng et al. 1999), as they are in the striatum (Cepeda and Levine 1998; Cepeda et al. 1993; Levine et al. 1996). Hence an important finding of the present study is that both a reduction of the fast, voltageindependent AMPA conductances (consistent with our previous analysis) and an enhancement in NMDA conductances result in increased stability.

Finally, both $I_{\mathrm{KS}}$ and $I_{\mathrm{HVA}}$ reduction might have a stabilizing effect under certain conditions: $I_{\mathrm{HVA}}$ via its double role in amplifying EPSPs (Seamans et al. 1997) and activating $\mathrm{Ca}^{2+}$ dependent $\mathrm{K}^{+}$currents (Schwindt and Crill 1997) and $I_{\mathrm{KS}}$ in neurons where this current makes a sufficiently high contribution to the total membrane conductance. A reduction in $I_{\mathrm{HVA}}$ also might be especially effective for stronger attractors firing 
at higher frequencies (because of the high $\mathrm{Ca}^{2+}$ influx, see RESULTS), whereas a reduction in $I_{\mathrm{KS}}$ might have its strongest impact on weak attractors firing at comparatively low frequencies (because $I_{\mathrm{KS}}$ increasingly inactivates at higher frequencies). A reduction in $\mathrm{N}$-type $\mathrm{Ca}^{2+}$ conductances furthermore might enhance stability by diminishing especially synaptic inputs to distal (upper layer) dendritic sites where mainly fibers from other association and higher sensory areas terminate (Durstewitz et al. 1999a; Yang and Seamans 1996).

In conclusion, the present study provides additional support for the notion that DA might change the integrative properties of single neurons and prefrontal networks in a way that allows them to maintain goal-related delay activity for longer periods of time and to protect working-memory representations from being wiped out by minor interfering events. Hence when an animal actively pursues a behaviorally important goal, high prefrontal DA levels might ensure that the behavior of the animal remains directed toward that goal. On the other hand, under conditions where a specific goal has not yet been selected or where a goal has been reached and hence goaldirected behavior should be terminated, high DA levels in the PFC might be counterproductive and might cause perseveration and behavioral stereotypies (Le Moal and Simon 1991; Roberts et al. 1994; Waddington and Daly 1993; Zahrt et al. 1997). Finally, it should be noted that DA causes a relative increase in stability but does not ensure absolute robustness (see Fig. 4). In general, the robustness of a goal-related representation in the PFC might reflect the importance or behavioral relevance of the current goal state.

\section{Behavioral performance and optimal DA levels}

Behavioral evidence suggests that there might be an optimal level of DA or of DA receptor stimulation in the PFC (Arnsten et al. 1994; Murphy et al. 1996a,b; Zahrt et al. 1997; but see Luciana et al. 1998; Müller et al. 1998). The present study suggests that working-memory deficits resulting from DA receptor blockade (Sawaguchi and Goldman-Rakic 1994; Seamans et al. 1998) or diminished DA input into the PFC (Brozoski et al. 1979; Simon et al. 1980) might be a direct consequence of the largely reduced stability of prefrontal representations and processes under these conditions.

On the other hand, working-memory deficits resulting from supranormal stimulation of dopaminergic receptors in the PFC (Murphy et al. 1996a,b; Zahrt et al. 1997) might arise on many different levels. For example, they might result from interactions of the PFC with other areas, e.g., because very high, sustained activity levels in the PFC trigger premature motor responses (Durstewitz et al. 1999a). Another possibility is that at supranormal DA levels, prefrontal representations become so stable that they persist even across trials, thus causing response perseveration and behavioral stereotypies as observed after, e.g., apomorphine injections (Durstewitz et al. 1999b; Le Moal and Simon 1991; Waddington and Daly 1993). Perseveration errors indeed seem to account for most of the diminished working-memory performance after supranormal DA receptor stimulation (Zahrt et al. 1997).

On the single-neuron level, an optimal DA level could result from different DA-dependent parameters exhibiting different dose-response-curves. For example, the DA-induced increase in GABAergic currents might saturate at higher levels than other DA-induced changes, resulting in a relative increase of the contribution of inhibition at very high levels of DA receptor stimulation that causes stability to decline again at these levels. A decrease in stability with an increase in $\mathrm{GABA}_{\mathrm{A}}$ conductances not accompanied by likewise changes in other DAmodulated parameters indeed occurred in our network simulations (see Fig. $5 A, 150 \%$ shift in $g_{\text {GABAA }}$ ). This interpretation also is supported tentatively by the finding of Williams and Goldman-Rakic (1995) that supranormal DA receptor stimulation, at least in the vicinity of the soma where mainly GABAergic inputs converge, might diminish delay activity.

\section{Experimental predictions of the model}

One way to test the predictions of the model in vivo is to place monkeys into a working-memory task with intervening stimuli as employed by Miller et al. (1996) and to inject locally into the PFC different concentrations of DA receptor antagonists while recording from PFC neurons. This should render delay-activity in the PFC more vulnerable to interference by intervening stimuli so that delay-activity should collapse after one of the intervening stimuli. In vivo experiments that test predictions of the model with regard to the separate contributions of DA-modulated synaptic conductances are also conceivable. A partial blockade of NMDA conductances should lead to a reduction in or a premature cessation of delay activity and should increase the vulnerability of delay activity with respect to interfering stimuli. Whether, in contrast, a partial blockade of AMPA receptors enhances robustness, might be more difficult to test because, depending on the relation between prefrontal DA level and AMPA channel modulation, at optimal DA levels a further reduction in AMPA currents might not have a large enough effect on stability. Finally, a partial blockade of $\mathrm{GABA}_{\mathrm{A}}$ conductances also should diminish working-memory performance, although it actually might enhance delay activity, because spontaneous activity in the PFC would be highly increased (causing the activation of irrelevant representations) and representations might persist between trials.

Another prediction of the present study is that DA in the PFC differentially affects task-related high-activity states in a working-memory context versus low-activity states occurring spontaneously outside any task context. This differential modulation was an intrinsic property of the voltage dependencies and kinetic properties of the conductances affected by DA and thus was related to the stability-enhancing effect of DA. There is some indirect evidence for this hypothesis: Sawaguchi et al. (1988, 1990a,b) found that DA strongly increases task-related activity in PFC neurons during working memory, whereas, in contrast, other researchers (Ferron et al. 1984; Godbout et al. 1991; Mantz et al. 1988; Pirot et al. 1992, 1996) found that stimulation of the ventral tegmental area or local DA application in the PFC caused a transient suppression of activity in anesthetized animals outside a behavioral context. Thus the observations in the latter studies might correspond to the suppression of spontaneous activity that occurred in the network model in the high DA condition. However, the animals in these studies were anesthetized with ketamine, which blocks NMDA conductances and thus one of the major excitatory effects of DA. Therefore more direct empirical tests are needed to demonstrate that DA within the same animals suppresses spontaneous 
but enhances task-related activity or at least enhances the latter more than the former.

Our results are also consistent with the finding that the subjective reward magnitude of an expected stimulus or situation, i.e., the behavioral importance of a current goal state, is correlated with the firing rate of prefrontal neurons, including those neurons that exhibit delay or anticipatory activity (Tremblay and Schultz 1999; Watanabe 1996). Because the behavioral importance (expected reward magnitude) of a stimulus also is reflected in the firing of dopaminergic midbrain neurons (Ljungberg et al. 1992; Schultz and Romo 1990; Schultz et al. 1993), these findings support the idea that DA enhances delay activity and increases the robustness of representations encoding goal-related information. In this sense, DA in the PFC might be interpreted as a signal that instructs the PFC to hold active and protect currently incoming information and preparatory processes that might be important in obtaining future rewards. The overall stabilization might depend on the importance of the goal and the expected magnitude of the reward.

We especially thank M. Eisele and D. Needleman for a thorough reading of this paper and for many helpful remarks.

D. Durstewitz was supported by a grant from the Deutscher Akademischer Austauschdienst (DAAD) within the Hochschulsonderprogramm III. J. K. Seamans was supported by a fellowship of the Natural Sciences and Engineering Research Council of Canada.

Address for reprint requests: D. Durstewitz, Salk Institute for Biological Studies, Computational Neurobiology Laboratory, 10010 N. Torrey Pines Rd., La Jolla, CA 92037.

Received 13 September 1999; accepted in final form 21 November 1999.

\section{REFERENCES}

Alzheimer, C., Schwindt, P. C., ANd Crill, W. E. Modal gating of $\mathrm{Na}^{+}$ channels as a mechanism of persistent $\mathrm{Na}^{+}$current in pyramidal neurons from rat and cat sensorimotor cortex. J. Neurosci. 13: 660-673, 1993.

Angulo, M. C., Lambolez, B., Audinat, E., Hestrin, S., and Rossier, J. Subunit composition, kinetic, and permeation properties of AMPA receptors in single neocortical nonpyramidal cells. J. Neurosci. 17: 6685-6696, 1997.

Arnsten, A. F., Cai, J. X., Murphy, B. L., and Goldman-Rakic, P. S. Dopamine D1 receptor mechanisms in the cognitive performance of young and aged monkeys. Psychopharmacology (Berl.) 116: 143-151, 1994.

AsaAd, W. F., Rainer, G., AND Miller, E. K. Neural activity in the primate prefrontal cortex during associative learning. Neuron 21: 1399-1407, 1998.

Berendse, H. W. AND GROENEWEgen, H. J. Restricted cortical termination fields of the midline and intralaminar thalamic nuclei in the rat. Neuroscience 42: 73-102, 1991.

Berger, B., Febvret, A., Greengard, P., and Goldman-Rakic, P. S. DARPP-32, a phosphoprotein enriched in dopaminoceptive neurons bearing dopamine D1 receptors: distribution in the cerebral cortex of the newborn and adult rhesus monkey. J. Comp. Neurol. 299: 327-348, 1990.

Berger, B., Gaspar, P., and Verney, C. Dopaminergic innervation of the cerebral cortex: unexpected differences between rodents and primates. Trends Neurosci. 14: 21-27, 1991.

Berger, B., Trottier, S., Verney, C., Gaspar, P., and Alvarez, C. Regional and laminar distribution of the dopamine and serotonin innervation in the macaque cerebral cortex: a radioautographic study. J. Comp. Neurol. 273: 99-119, 1988

Bergson, C., Mrzljak, L., Smiley, J. F., Pappy, M., Levenson, R., and GOLDMAN RAKIC, P. S. Regional, cellular, and subcellular variations in the distribution of D1 and D5 dopamine receptors in primate brain. J. Neurosci. 15: 7821-7836, 1995.

Black, J. A., Kocsis, J. D., AND WaXman, S. G. Ion channel organization of the myelinated fiber. Trends Neurosci. 13: 48-54, 1990.

Bodner, M., ZHOU, Y. D., AND Fuster, J. M. Binary mapping of cortical spike trains in short-term memory. J. Neurophysiol. 77: 2219-2222, 1997.

Brody, C. D., HernándeZ, A., Lemus, L., AND Romo, R. Interactions between single prefrontal neurons during parametric working memory. Soc. Neurosci. Abstr. 25: 1814, 1999
Brown, A. M., Schwindt, P. C., AND Crill, W. E. Voltage dependence and activation kinetics of pharmacologically defined components of the highthreshold calcium current in rat neocortical neurons. J. Neurophysiol. 70: 1530-1543, 1993.

Brozoski, T. J., Brown, R. M., Rosvold, H. E., And Goldman, P. S. Cognitive deficit caused by regional depletion of dopamine in prefrontal cortex of rhesus monkey. Science 205: 929-932, 1979.

Cepeda, C., Buchwald, N. A., And Levine, M. S. Neuromodulatory actions of dopamine in the neostriatum are dependent upon the excitatory amino acid receptor subtypes activated. Proc. Natl. Acad. Sci. USA 90: 9576-9580, 1993.

Cepeda, C. And Levine, M. S. Dopamine and $N$-methyl-D-aspartate receptor interactions in the neostriatum. Dev. Neurosci. 20: 1-18, 1998.

Cepeda, C., Radisavljevic, Z., Peacock, W., Levine, M. S., and Buchwald, N. A. Differential modulation by dopamine of responses evoked by excitatory amino acids in human cortex. Synapse 11: 330-341, 1992.

Cohen, J. D., Perlstein, W. M., Braver, T. S., Nystrom, L. E., Noll, D. C., JoNidES, J., AND SMITH, E. E. Temporal dynamics of brain activation during a working memory task. Nature 386: 604-608, 1997.

Colbert, C. M. And Johnston, D. Axonal action-potential initiation and $\mathrm{Na}^{+}$ channel densities in the soma and axon initial segment of subicular pyramidal neurons. J. Neurosci. 16: 6676-6686, 1996.

Constantinidis, C., Franowicz, M. N., and Goldman-Rakic, P. S. Multiple electrode analysis of local circuitry in the primate prefrontal cortex during spatial working memory. Soc. Neurosci. Abstr. 25: 97, 1999.

Cummins, T. R., XIA, Y., AND Haddad, G. G. Functional properties of rat and human neocortical voltage-sensitive sodium currents. J. Neurophysiol. 71: 1052-1064, 1994

Dehaene, S., Jonides, J., Smith, E. E., ANd Spitzer, M. Thinking and problem solving. In: Fundamental Neuroscience, edited by M. J. Zigmond, F. E. Bloom, S. C. Landis, J. L. Roberts, and L. R. Squire. San Diego: Academic, 1999 , p. $1543-1564$.

Destexhe, A. And Paré, D. Impact of network activity on the integrative properties of neocortical pyramidal neurons in vivo. J. Neurophysiol. 81: $1531-1547,1999$

Di Pellegrino, G. and Wise, S. P. Visuospatial versus visuomotor activity in the premotor and prefrontal cortex of a primate. J. Neurosci. 13: 1227-1243, 1993.

Dias, R., Robbins, T. W., AND RoberTs, A. C. Dissociable forms of inhibitory control within prefrontal cortex with an analog of the Wisconsin card sort test: restriction to novel situations and independence from "on-line" processing. J. Neurosci. 17: 9285-9297, 1997.

Douglas, R. J. AND Martin, K.A.C. Neocortex. In: The Synaptic Organization of the Brain, edited by G. M. Shepherd. New York: Oxford Univ. Press, 1990 , p. 389-438.

DuRSTEWITZ, D., KelC, M., AND GÜNTÜRKÜN, O. A neurocomputational theory of the dopaminergic modulation of working memory functions. J. Neurosci. 19: 2807-2822, 1999a.

DURSTEWITZ, D., KRÖNER, S., AND GÜNTÜRKÜN, O. The dopaminergic innervation of the avian telencephalon. Prog. Neurobiol. 59: 161-195, 1999b.

Ferron, A., Thierry, A. M., Le Douarin, C., AND Glowinski, J. Inhibitory influence of the mesocortical dopaminergic system on spontaneous activity or excitatory response induced from the thalamic mediodorsal nucleus in the rat medial prefrontal cortex. Brain Res. 302: 257-265, 1984.

Fleidervish, I. A., Friedman, A., AND GutNick, M. J. Slow inactivation of $\mathrm{Na}^{+}$current and slow cumulative spike adaptation in mouse and guinea-pig neocortical neurones in slices. J. Physiol. (Lond.) 493: 83-97, 1996.

Formenti, A., Martina, M., Plebani, A., and Mancia, M. Multiple modulatory effects of dopamine on calcium channel kinetics in adult rat sensory neurons. J. Physiol. (Lond.) 509: 395-409, 1998.

Funahashi, S., Bruce, C. J., AND Goldman RaKic, P. S. Mnemonic coding of visual space in the monkey's dorsolateral prefrontal cortex. J. Neurophysiol. 61: 331-349, 1989

FunAHASHI, S. AND KuBOtA, K. Working memory and prefrontal cortex. Neurosci. Res. 21: 1-11, 1994.

FusteR, J. M. Unit activity in prefrontal cortex during delayed-response performance: neuronal correlates of transient memory. J. Neurophysiol. 36: 61-78, 1973

Fuster, J. M. The Prefrontal Cortex: Anatomy, Physiology, and Neuropsychology of the Frontal Lobe. New York: Raven Press, 1989.

Fuster, J. M., Bauer, R. H., AND JeRvey, J. P. Functional interactions between inferotemporal and prefrontal cortex in a cognitive task. Brain Res. 330: $299-307,1985$ 
Gabbott, P. L., Dickie, B. G., Vaid, R. R., Headlam, A. J., and Bacon, S. J. Local-circuit neurones in the medial prefrontal cortex (areas 25, 32 and 24b) in the rat: morphology and quantitative distribution. J. Comp. Neurol. 377: 465-499, 1997.

Godbout, R., Mantz, J., Pirot, S., Glowinski, J., And Thierry, A.-M. Inhibitory influence of the mesocortical dopaminergic neurons on their target cells: electrophysiological and pharmacological characterization. J. Pharmacol. Exp. Ther. 258: 728-738, 1991.

Goldman-RAKIC, P. S. Cellular and circuit basis of working memory in prefrontal cortex of nonhuman primates. In: Progress in Brain Research. The Prefrontal Cortex: Its Structure, Function, and Pathology, edited by H.B.M. Uylings, C. G. Van Eden, J.P.C. De Bruin, M. A. Corner, and M.G.P. Feenstra. Oxford: Elsevier, 1990, vol. 85, p. 325-336.

GoldMAN-RAKIC, P. S. Regional and cellular fractionation of working memory. Proc. Natl. Acad. Sci. USA 93: 13473-13480, 1996.

GoldMAN-RAKIC, P. S. Topography of cognition: parallel distributed networks in primate association cortex. Annu. Rev. Neurosci. 11: 137-156, 1988.

GoldMAN-RAKIC, P. S. Toward a circuit model of working. Memory and the guidance of voluntary motor action. In: Models of Information Processing in the Basal Ganglia, edited by J. C. Houk, J. L. Davis, and D. G. Beiser. Cambridge, MA: MIT Press, 1995, p. 131-148.

Goldman-Rakic, P. S., Lidow, M. S., Smiley, J. F., And Williams, M. S. The anatomy of dopamine in monkey and human prefrontal cortex. J. Neural Transm. 36: 163-177, 1992.

Gorelova, N. AND YANG, C. R. Dopamine D1 receptor stimulation modulates a slowly inactivating $\mathrm{Na}^{+}$current in layer V-VI prefrontal cortical (PFC) neurons. Soc. Neurosci. Abstr. 23: 1771, 1997.

Gorelova, N. AND YANG, C. R. Dopamine increases the excitability of fast-spiking interneurons in rat medial prefrontal cortex via D1/5 receptor activation. Soc. Neurosci. Abstr. 24: 350, 1998

Gulledge, A. T. AND JAFFe, D. B. Dopamine decreases the excitability of layer V pyramidal cells in the rat prefrontal cortex. J. Neurosci. 18: 9139-9151, 1998.

GÜNTÜRKÜN, O. AND DuRstewiTz, D. Multimodal areas of the avian forebrain-blueprints for cognition? In: Evolution of Brain and Cognition, edited by G. Roth and M. Wullimann. New York: Scientific American Press. In press.

HAMmOND, C. AND CRÉPEL, F. Evidence for a slowly inactivating $\mathrm{K}^{+}$current in prefrontal cortical cells. Eur. J. Neurosci. 4: 1087-1092, 1992.

HeBB, D. O. The Organization of Behavior. New York: Wiley, 1949.

Hell, J. W., Westenbroek, R. E., Warner, C., Ahlijanian, M. K., Prystay, W., Gilbert, M. M., Snutch, T. P., and Catterall, W. A. Identification and differential subcellular localization of the neuronal class C and class D L-type calcium channel a1 subunits. J. Cell. Biol. 123: 949-962, 1993.

Helmchen, F., Imoto, K., and SAKMANn, B. $\mathrm{Ca}^{2+}$ buffering and action potential-evoked $\mathrm{Ca}^{2+}$ signaling in dendrites of pyramidal neurons. Biophys. J. 70: 1069-1081, 1996.

Hoffman, D. A., Magee, J. C., Colbert, C. M., and Johnston, D. K ${ }^{+}$channel regulation of signal propagation in dendrites of hippocampal pyramidal neurons. Nature 387: 869-875, 1997.

Hsu, K. S. Characterization of dopamine receptors mediating inhibition of excitatory synaptic transmission in the rat hippocampal slice. J. Neurophysiol. 76: 1887-1895, 1996.

Huguenard, J. R., Haill, O. P., and Prince, D. A. Sodium channels in dendrites of rat cortical pyramidal neurons. Proc. Natl. Acad. Sci. USA 86: 2473-2477, 1989.

Huguenard, J. R. And Prince, D. A. Slow inactivation of a TEA-sensitive K current in acutely isolated rat thalamic relay neurons. J. Neurophysiol. 66: 1316-1328, 1991.

Isseroff, A., Schwartz, M. L., Dekker, J. J., and Goldman Rakic, P. S. Columnar organization of callosal and associational projections from rat frontal cortex. Brain Res. 293: 213-223, 1984.

IVERSEN, S. D. AND Mishrin, M. Perseverative interference in monkeys following selective lesions of the inferior prefrontal convexity. Exp. Brain Res. 11: 376-386, 1970.

JoyCE, J. N., GOLDSMith, S., AND MuRRAY, A. Neuroanatomical localization of $D_{1}$ versus $D_{2}$ receptors: similar organization in the basal ganglia of the rat, cat and human and disparate organization in the cortex and limbic system. In: $D_{1}: D_{2}$ Dopamine Receptor Interactions, edited by J. L. Waddington. London: Academic, 1993, p. 23-49.

Jung, M. W., Qin, Y., McNaughton, B. L., and Barnes, C. A. Firing characteristics of deep layer neurons in prefrontal cortex in rats performing spatial working memory tasks. Cereb. Cortex 8: 437-450, 1998.
KaWAGUCHI, Y. Groupings of nonpyramidal and pyramidal cells with specific physiological and morphological characteristics in rat frontal cortex. J. Neurophysiol. 69: 416-431, 1993.

KaWAGUCHI, Y. Physiological subgroups of nonpyramidal cells with specific morphological characteristics in layer II/III of rat frontal cortex. J. Neurosci. 15: 2638-2655, 1995.

KawAGUCHI, Y. AND KuBota, Y. GABAergic cell subtypes and their synaptic connections in rat frontal cortex. Cereb. Cortex 7: 476-486, 1997.

Kesner, R. P., Hopkins, R. O., And Fineman, B. Item and order dissociation in humans with prefrontal cortex damage. Neuropsychologia 32: 881-891, 1994.

Kita, H., Oda, K., AND Murase, K. Effects of dopamine agonists and antagonists on optical responses evoked in rat frontal cortex slices after stimulation of the subcortical white matter. Exp. Brain Res. 125: 383-388, 1999.

Koechlin, E., Basso, G., Pietrini, P., Panzer, S., and Grafman, J. The role of the anterior prefrontal cortex in human cognition. Nature 399: 148-151, 1999.

KRITZER, M. F. AND GOLDMAN-RAKIC, P. S. Intrinsic circuit organization of the major layers and sublayers of the dorsolateral prefrontal cortex in the rhesus monkey. J. Comp. Neurol. 359: 131-143, 1995.

Kuroda, M., Murakami, K., Igarashi, H., and OKada, A. The convergence of axon terminals from the mediodorsal thalamic nucleus and ventral tegmental area on pyramidal cells in layer V of the rat prelimbic cortex. Eur. J. Neurosci. 8: 1340-1349, 1996.

Kuroda, M., Murakami, K., Oda, S., Shinkai, M., and Kishi, K. Direct synaptic connections between thalamocortical axon terminals from the mediodorsal thalamic nucleus (MD) and corticothalamic neurons to MD in the prefrontal cortex. Brain Res. 612: 339-344, 1993.

LARKMAn, A. U. Dendritic morphology of pyramidal neurones of the visual cortex of the rat. III. Spine distributions. J. Comp. Neurol. 306: 332-343, 1991.

LAW-Tho, D., HiRsch, J. C., AND CREPEl, F. Dopamine modulation of synaptic transmission in rat prefrontal cortex: an in vitro electrophysiological study. Neurosci. Res. 21: 151-160, 1994.

Le Moal, M. And Simon, H. Mesocorticolimbic dopaminergic network: functional and regulatory roles. Physiol. Rev. 71: 155-234, 1991.

Levine, M. S., Li, Z., Cepeda, C., Cromwell, H. C., and Altemus, K. L. Neuromodulatory actions of dopamine on synaptically-evoked neostriatal responses in slices. Synapse 24: 65-78, 1996.

LevitT, J. B., Lewis, D. A., YoshiokA, T., AND Lund, J. Topography of pyramidal neuron intrinsic connections in macaque monkey prefrontal cortex (area 9 and 46). J. Comp. Neurol. 338: 360-376, 1993.

LeVy, W. B. AND STEWARD, O. Temporal contiguity requirements for longterm associative potentiation/depression in the hippocampus. Neuroscience 8: 791-797, 1983.

Lewis, D. A., Hayes, T. L., Lund, J. S., AND Oeth, K. M. Dopamine and the neural circuitry of primate prefrontal cortex: implications for schizophrenia research. Neuropsychopharmacology 6: 127-134, 1992.

Lidow, M. S., Goldman Rakic, P. S., Gallager, D. W., and Rakic, P. Distribution of dopaminergic receptors in the primate cerebral cortex: quantitative autoradiographic analysis using $[3 \mathrm{H}]$ raclopride, $[3 \mathrm{H}]$ spiperone and [3H]SCH23390. Neuroscience 40: 657-671, 1991.

Lidow, M. S., WANG, F., CAO, Y., AND Goldman RaKIC, P. S. Layer V neurons bear the majority of mRNAs encoding the five distinct dopamine receptor subtypes in the primate prefrontal cortex. Synapse 28: 10-20, 1998

LING, D.S.F. AND BENARDO, L. S. Synchronous firing of inhibitory interneurons results in saturation of fast $\mathrm{GABA}_{\mathrm{A}}$ IPSC magnitude but not saturation of fast inhibitory efficacy in rat neocortical pyramidal cells. Synapse 28: 91-102, 1998.

Ljungberg, T., Apicella, P., And Schultz, W. Responses of monkey dopamine neurons during learning of behavioral reactions. J. Neurophysiol. 67: 145-163, 1992.

LÜbKe, J., Markram, H., Frotscher, M., and SAKmann, B. Frequency and dendritic distribution of autapses established by layer $\mathrm{V}$ pyramidal neurons in the developing rat neocortex: comparison with synaptic innervation of adjacent neurons of the same class. J. Neurosci. 16: 3209-3218, 1996.

Luciana, M., Collins, P. F., and Depue, R. A. Opposing roles for dopamine and serotonin in the modulation of human spatial working memory functions. Cereb. Cortex 8: 218-226, 1998.

LytTon, W. W. AND Sejnowski, T. J. Simulations of cortical pyramidal neurons synchronized by inhibitory interneurons. J. Neurophysiol. 66: 1059-1079, 1991. 
Magee, J. C. AND Johnston, D. Characterization of single voltage-gated $\mathrm{Na}^{+}$ and $\mathrm{Ca}^{2+}$ channels in apical dendrites of rat CA1 pyramidal neurons. J. Physiol. (Lond.) 487.1: 67-90, 1995.

Mantz, J., Milla, C., Glowinski, J., And Thierry, A. M. Differential effects of ascending neurons containing dopamine and noradrenaline in the control of spontaneous activity and of evoked responses in the rat prefrontal cortex. Neuroscience 27: 517-526, 1988

Markram, H., Lübke, J., Frotscher, M., Roth, A., and Sakmann, B. Physiology and anatomy of synaptic connections between thick tufted pyramidal neurones in the developing rat neocortex. J. Physiol. (Lond.) 500.2: 409-440, 1997a.

Markram, H., Lübke, J., Frotscher, M., and Sakmann, B. Regulation of synaptic efficacy by coincidence of postsynaptic APs and EPSPs. Science 275: 213-215, 1997b.

Martina, M. AND Jonas, P. Functional differences in $\mathrm{Na}^{+}$channel gating between fast-spiking interneurones and principal neurones of rat hippocampus. J. Physiol. (Lond.) 505: 593-603, 1997.

MeL, B. W. Synaptic integration in an excitable dendritic tree. J. Neurophysiol. 70: $1086-1101,1993$

Melchitzky, D. S., Sesack, S. R., Pucak, M. L., and Lewis, D. A. Synaptic targets of pyramidal neurons providing intrinsic horizontal connections in monkey prefrontal cortex. J. Comp. Neurol. 390: 211-224, 1998.

Miller, E. K., ERickson, C. A., And Desimone, R. Neural mechanisms of visual working memory in prefrontal cortex of the macaque. J. Neurosci. 16: 5154-5167, 1996.

Mitner, B. And Petrides, M. Behavioural effects of frontal-lobe lesions in man. Trends Neurosci. 7: 403-407, 1984

Mittmann, T., Linton, S. M., Schwindt, P., and Crill, W. Evidence for persistent $\mathrm{Na}^{+}$current in apical dendrites of rat neocortical neurons from imaging of $\mathrm{Na}^{+}$-sensitive dye. J. Neurophysiol. 78: 1188-1192, 1997.

MoORE, H., LAVIN, A., AND GRACE, A. A. Interactions between dopamine and NMDA delivered locally by microdialysis during in vivo intracellular recordings of rat prefrontal cortical neurons. Soc. Neurosci. Abstr. 24: 2061, 1998.

Müller, U., von Cramon, D. Y., And Pollmann, S. D1- versus D2-receptor modulation of visuospatial working memory in humans. J. Neurosci. 18: 2720-2728, 1998

Muly, E. C., Szigeti, K., AND Goldman-RaKic, P. S. D 1 receptor in interneurons of macaque prefrontal cortex: distribution and subcellular localization. J. Neurosci. 18: 10553-10565, 1998.

Murphy, B. L., Arnsten, A.F.T., Goldman-Rakic, P. S., and Roth, R. H. Increased dopamine turnover in the prefrontal cortex impairs spatial working memory performance in rats and monkeys. Proc. Natl. Acad. Sci. USA 93: 1325-1329, 1996a.

Murphy, B. L., Arnsten, A.F.T., Jentsch, J. D., And Roth, R. H. Dopamine and spatial working memory in rats and monkeys: pharmacological reversal of stress-induced impairment. J. Neurosci. 16: 7768-7775, 1996b.

Nisenbaum, E. S., Mermelstein, P. G., Wilson, C. J., And Surmeier, D. J. Selective blockade of a slowly inactivating potassium current in striatal neurons by (+/-) 6-chloro-APB hydrobromide (SKF82958). Synapse 29: 213-224, 1998

OtMAKHOVA, N. A. AND Lisman, J. E. Dopamine selectively inhibits the direct cortical pathway to the CA1 hippocampal region. J. Neurosci. 19: 14371445,1999

Pandya, D. N. and Yeterian, E. H. Prefrontal cortex in relation to other cortical areas in rhesus monkey: architecture and connections. In: Progress in Brain Research. The Prefrontal Cortex: Its Structure, Function, and Pathology, edited by H.B.M. Uylings, C. G. Van Eden, J.P.C. De Bruin, M. A. Corner, and M.G.P. Feenstra. Oxford: Elsevier, 1990, vol. 85, p. 63-94.

Paré, D., Shink, E., Gaudreau, H., Destexhe, A., and Lang, E. J. Impact of spontaneous synaptic activity on the resting properties of cat neocortical pyramidal neurons in vivo. J. Neurophysiol. 79: 1450-1460, 1998.

Penit-Soria, J., Audinat, E., ANd Crepel, F. Excitation of rat prefrontal cortical neurons by dopamine: an in vitro electrophysiological study. Brain Res. 425: 263-274, 1987.

PETRIDES, M. Impairments on nonspatial self-ordered and externally ordered working memory tasks after lesions of the mid-dorsal part of the lateral frontal cortex in the monkey. J. Neurosci. 15: 359-375, 1995.

Pirot, S., Glowinski, J., AND ThierRy, A.-M. Mediodorsal thalamic evoked responses in the rat prefrontal cortex: influence of the mesocortical DA system. Neuroreport 7: 1437-1441, 1996.
Pirot, S., Godbout, R., Mantz, J., Tassin, J.-P., Glowinski, J., And Thierry, A.-M. Inhibitory effects of ventral tegmental area stimulation on the activity of prefrontal cortical neurons: evidence for the involvement of both dopaminergic and GABAergic components. Neuroscience 49: 857-865, 1992.

Press, W. H., Teukolsky, S. A., Vetterling, W. T., Flannery, B. P. Numerical Recipes in C. Cambridge, MA: University Press, 1992.

PucAK, M. L., LeVITT, J. B., Lund, J. S., AND LewIS, D. A. Patterns of intrinsic and associational circuitry in monkey prefrontal cortex. J. Comp. Neurol. 376: 614-630, 1996.

QuintanA, J. And Fuster, J. M. From perception to action: temporal integrative functions of prefrontal and parietal neurons. Cereb. Cortex 9: 213-221, 1999.

Quintana, J., Yajeya, J., AND Fuster, J. M. Prefrontal representation of stimulus attributes during delay tasks. I. Unit activity in cross-temporal integration of sensory and sensory-motor information. Brain Res. 474: 211-221, 1988

Rainer, G., AsaAd, W. F., AND Miller, E. K. Memory fields of neurons in the primate prefrontal cortex. Proc. Natl. Acad. Sci. USA 95: 15008-15013, $1998 \mathrm{a}$

Rainer, G., AsaAd, W. F., And Miller, E. K. Selective representation of relevant information by neurons in the primate prefrontal cortex. Nature 393: 577-579, 1998b.

Rainer, G., RaO, S. C., And Miller, E. K. Prospective coding for objects in primate prefrontal cortex. J. Neurosci. 19: 5493-5505, 1999.

RALL, W. Cable theory for dendritic neurons. In: Methods in Neuronal Modeling: From Synapses to Networks, edited by C. Koch and I. Segev. Cambridge, MA: MIT Press, 1989, p. 9-62.

RAO, S. C., RAINER, G., AND MilleR, E. K. Integration of what and where in the primate prefrontal cortex. Science 276: 821-824, 1997.

RAO, S. C., WILliams, G. V., AND GoldMAN-RAKIC, P. S. Isodirectional tuning of adjacent interneurons and pyramidal cells during working memory: evidence for microcolumnar organization in PFC. J. Neurophysiol. 81: 1903-1916, 1999.

RÉTAux, S., Besson, M. J., ANd Penit-Soria, J. Opposing effects of dopamine D2 receptor stimulation on the spontaneous and the electrically evoked release of $\left[{ }^{3} \mathrm{H}\right] \mathrm{GABA}$ on rat prefrontal cortex slices. Neuroscience 42 : 61-71, 1991

RHodes, P. AND GRAY, C. M. Simulations of intrinsically bursting neocortical pyramidal neurons. Neural Comput. 6: 1086-1110, 1994.

Roberts, A. C., De Salvia, M. A., Wilkinson, L. S., Collins, P., Muir, J. L., EveritT, B. J., AND Robins, T. W. 6-hydroxydopamine lesions of the prefrontal cortex in monkeys enhance performance on an analog of the Wisconsin Card Sorting Test: possible interactions with subcortical dopamine. J. Neurosci. 14: 2531-2544, 1994.

Rosenkilde, C. E., BAuER, R. H., AND Fuster, J. M. Single cell activity in ventral prefrontal cortex of behaving monkeys. Brain Res. 209: 375-394, 1981.

$\mathrm{SAH}, \mathrm{P}$. Role of calcium influx and buffering in the kinetics of a $\mathrm{Ca}^{2+}$-activated $\mathrm{K}^{+}$current in rat vagal motoneurons. J. Neurophysiol. 68: 2237-2247, 1992.

SAWAGUCHI, T. AND GoldMAN-RAKIC, P. S. The role of D1-dopamine receptor in working memory: local injections of dopamine antagonists into the prefrontal cortex of rhesus monkeys performing an oculomotor delayedresponse task. J. Neurophysiol. 71: 515-528, 1994.

Sawaguchi, T., Matsumura, M., and Kubota, K. Dopamine enhances the neuronal activity of spatial short-term memory task in the primate prefrontal cortex. Neurosci. Res. 5: 465-473, 1988.

Sawaguchi, T., Matsumura, M., and Kubota, K. Catecholaminergic effects on neuronal activity related to a delayed response task in monkey prefrontal cortex. J. Neurophysiol. 63: 1385-1400, 1990a.

Sawaguchi, T., Matsumura, M., and Kubota, K. Effects of dopamine antagonists on neuronal activity related to a delayed response task in monkey prefrontal cortex. J. Neurophysiol. 63: 1401-1412, 1990b.

Schiller, J., Helmchen, F., and Sakmann, B. Spatial profile of dendritic calcium transients evoked by action potentials in rat neocortical pyramidal neurones. J. Physiol. (Lond.) 487: 583-600, 1995.

Schultz, W., Apicella, P., AND Ljungberg, T. Responses of monkey dopamine neurons to reward and conditioned stimuli during successive steps of learning a delayed response task. J. Neurosci. 13: 900-913, 1993.

SCHULTZ, W. AND ROMO, R. Dopamine neurons of the monkey midbrain: contingencies of responses to stimuli eliciting immediate behavioral reactions. J. Neurophysiol. 63: 607-624, 1990.

SCHwindT, P. C. Ionic currents governing input-output relations of Betz cells. In: Single Neuron Computation, edited by T. McKenna, J. Davis, and S. F. Zornetzer. Boston, MA: Academic, 1992, p. 235-258. 
Schwindt, P. C. AND CRILl, W. E. Amplification of synaptic current by persistent sodium conductance in apical dendrite of neocortical neurons. J. Neurophysiol. 74: 2220-2224, 1995.

SCHWINDT, P. AND CRILL, W. Equivalence of amplified current flowing from dendrite to soma measured by alteration of repetitive firing and by voltage clamp in layer 5 pyramidal neurons. J. Neurophysiol. 76: 3731-3739, 1996.

SCHWINDT, P. C. AND CRILL, W. E. Modification of current transmitted from apical dendrite to soma by blockade of voltage- and $\mathrm{Ca}^{2+}$-dependent conductances in rat neocortical pyramidal neurons. J. Neurophysiol. 78: 187-198, 1997.

Seamans, J. K., Durstewitz, D., And Sejnowski, T. J. State-dependence of dopamine D1 receptor modulation in prefrontal cortex neurons. Proc. Joint Symp Neural Comput. 9: 128-135, 1999.

Seamans, J. K., Floresco, S. B., AND Phillips, A. G. D1 receptor modulation of hippocampal-prefrontal cortical circuits integrating spatial memory with executive functions in the rat. J. Neurosci. 18: 1613-1621, 1998.

Seamans, J. K., Gorelova, N. A., And Yang, C. R. Contributions of voltagegated $\mathrm{Ca}^{2+}$ channels in the proximal versus distal dendrites to synaptic integration in prefrontal cortical neurons. J. Neurosci. 17: 5936-5948, 1997.

Sesack, S. R., Hawrylak, V. A., Melchitzky, D. S., and Lewis, D. A. Dopamine innervation of a subclass of local circuit neurons in monkey prefrontal cortex: ultrastructural analysis of tyrosine hydroxylase and parvalbumin immunoreactive structures. Cereb. Cortex 8: 614-622, 1998.

Shadlen, M. N. AND Newsome, W. T. Noise, neural codes and cortical organization. Curr. Opin. Neurobiol. 4: 569-579, 1994.

Shi, W.-X., Zheng, P., Liang, X.-F., And Bunney, B. S. Characterization of dopamine-induced depolarization of prefrontal cortical neurons. Synapse 26: 415-422, 1997.

Simon, H., Scatton, B., and Le Moal, M. Dopaminergic A10 neurones are involved in cognitive functions. Nature 286: 150-151, 1980.

Smiley, J. F., Levey, A. I., Ciliax, B. J., and Goldman Rakic, P. S. D1 dopamine receptor immunoreactivity in human and monkey cerebral cortex: predominant and extrasynaptic localization in dendritic spines. Proc. Natl. Acad. Sci. USA 91: 5720-5724, 1994.

SOFTKY, W. AND Koch, C. The highly irregular firing of cortical cells is inconsistent with temporal integration of random EPSPs. J. Neurosci. 13: $334-350,1993$

Spain, W. J., Schwindt, P. C., AND CRILl, W. E. Two transient potassium currents in layer $\mathrm{V}$ pyramidal neurones from cat sensorimotor cortex. J. Physiol. (Lond.) 434: 591-607, 1991.

Spruston, N., JafFe, D. B., and Johnston, D. Dendritic attenuation of synaptic potentials and currents: the role of passive membrane properties. Trends Neurosci. 17: 161-166, 1994.

Spruston, N., Jonas, P., AND SAKmann, B. Dendritic glutamate receptor channels in rat hippocampal CA3 and CA1 pyramidal neurons. J. Physiol. (Lond.) 482: 325-352, 1995a

Spruston, N., Schiller, Y., Stuart, G., and Sakmann, B. Activity-dependent action potential invasion and calcium influx into hippocampal CA1 dendrites. Science 268: 297-300, 1995b.

Stafstrom, C. E., Schwindt, P. C., Chubb, M. C., and Crill, W. E. Properties of persistent sodium conductance and calcium conductance of layer $\mathrm{V}$ neurons from cat sensorimotor cortex in vitro. J. Neurophysiol. 53: 153-170, 1985.

StUART, G. J. AND SAKMANN, B. Active propagation of somatic action potentials into neocortical pyramidal cell dendrites. Nature 367: 69-72, 1994.

StUART, G. AND SAKMAnN, B. Amplification of EPSPs by axosomatic sodium channels in neocortical pyramidal neurons. Neuron 15: 1065-1076, 1995.

StuART, G. AND SPRUSTon, N. Determinants of voltage attenuation in neocortical pyramidal neuron dendrites. J. Neurosci. 18: 3501-3510, 1998.

Surmeier, D. J., Bargas, J., Hemmings, H.C.J., NaIRn, A. C., AND GreEngard, P. Modulation of calcium currents by a $\mathrm{D}_{1}$ dopaminergic protein kinase/ phosphatase cascade in rat neostriatal neurons. Neuron 14: 385-397, 1995.

SwANSON, L. W. A direct projection from Ammon's horn to prefrontal cortex in the rat. Brain Res. 217: 150-154, 1981.

Tarczy-Hornoch, K., Martin, K. A., Jack, J. J., and Stratford, K. J. Synaptic interactions between smooth and spiny neurones in layer 4 of cat visual cortex in vitro. J. Physiol. (Lond.) 508: 351-363, 1998.
Thomson, A. M. And Deuchars, J. Synaptic interactions in neocortical local circuits: dual intracellular recordings in vitro. Cereb. Cortex 7: 510-522, 1997.

Thomson, A. M., West, D. C., Hahn, J., And Deuchars, J. Single axon IPSPs elicited in pyramidal cells by three classes of interneurones in slices of rat neocortex. J. Physiol. (Lond.) 496: 81-102, 1996.

TREMBLAY, L. AND SCHULTZ, W. Relative reward preference in primate orbitofrontal cortex. Nature 398: 704-708, 1999.

WadDington, J. L. AND DALY, S. A. Regulation of unconditioned motor behaviour by D1:D2 interactions. In: D1:D2 Dopamine Receptor Interactions, edited by J. L. Waddington. Toronto: Academic, 1993, p. 51-78.

WANG, X.-J. Ionic basis for intrinsic $40 \mathrm{~Hz}$ neuronal oscillations. Neuroreport 5: 221-224, 1993.

Warman, E. N., DuRAnd, D. M., AND YuEN, G.L.F. Reconstruction of hippocampal CA1 pyramidal cell electrophysiology by computer simulation. J. Neurophysiol. 71: 2033-2045, 1994.

WATANABE, M. Reward expectancy in primate prefrontal neurons. Nature 382: 629-632, 1996.

Watanabe, M., Kodama, T., And HikosaKa, K. Increase of extracellular dopamine in primate prefrontal cortex during a working memory task. J. Neurophysiol. 78: 2795-2798, 1997.

Westenbroek, R. E., Ahlijanian, M. K., and Catterall, W. A. Clustering of L-type $\mathrm{Ca}^{2+}$ channels at the base of major dendrites in hippocampal pyramidal neurons. Nature 347: 281-284, 1990.

Westenbroek, R. E., Hell, J. W., Warner, C., Dubel, S. J., Snutch, T. P. AND CATTERAll, W. A. Biochemical properties and subcellular distribution of an N-type calcium channel a1 subunit. Neuron 9: 1099-1115, 1992.

Westenbroek, R. E., Merrick, D. K., and Catterall, W. A. Differential subcellular localization of the $\mathrm{R}_{\mathrm{I}}$ and $\mathrm{R}_{\mathrm{II}} \mathrm{Na}^{+}$channel subtypes in central neurons. Neuron 3: 695-704, 1989.

Williams, G. V. AND GoldMAN-RAKIC, P. S. Modulation of memory fields by dopamine D1 receptors in prefrontal cortex. Nature 376: 572-575, 1995.

Wilson, F.A.W., Scalaidhe, S.P.O., and Goldman-RaKic, P. S. Functional synergism between putative $\gamma$-aminobutyrate-containing neurons and pyramidal neurons in prefrontal cortex. Proc. Natl. Acad. Sci. USA 91: 4009-4013, 1994.

Yamada, W. M., Koch, C., AND Adams, P. R. Multiple channels and calcium dynamics. In: Methods in Neuronal Modeling: From Synapses to Networks, edited by C. Koch and I. Segev. Cambridge, MA: MIT Press, 1989, p. 97-133.

YanG, C. R. And Seamans, J. K. Dopamine D1 receptor actions in layers V-VI rat prefrontal cortex neurons in vitro: modulation of dendritic-somatic signal integration. J. Neurosci. 16: 1922-1935, 1996.

YANG, C. R., SeAmans, J. K., AND Gorelova, N. Electrophysiological and morphological properties of layers V-VI principal pyramidal cells in rat prefrontal cortex in vitro. J. Neurosci. 16: 1904-1921, 1996.

Yang, C. R., Seamans, J. K., and Gorelova, N. Mechanisms of dopamine (DA) modulation of GABAergic inputs to rat layer V-VI pyramidal prefrontal cortical (PFC) neurons in vitro. Soc. Neurosci. Abstr. 23: 1771, 1997.

Yang, C. R., Seamans, J. K., AND Gorelova, N. Dopamine D1/5 receptor activation influences $\mathrm{N}$ - and $\mathrm{L}$-type $\mathrm{Ca}^{2+}$ channels to modulate dendritic $\mathrm{Ca}^{2+}$ potentials in pyramidal prefrontal cortex (PFC) neurons. Soc. Neurosci. Abstr. 24: 854, 1998.

Yuste, R., Gutnick, M. J., SaAR, D., Delaney, K. R., And Tank, D. W. Ca ${ }^{2+}$ accumulations in dendrites of neocortical pyramidal neurons: an apical band and evidence for two functional compartments. Neuron 13: 23-43, 1994.

Zahrt, J., TAYLOR, J. R., Mathew, R. G., and ARnSten, A.F.T. Supranormal stimulation of $\mathrm{D}_{1}$ dopamine receptors in the rodent prefrontal cortex impairs spatial working memory performance. J. Neurosci. 17: 8528-8535, 1997.

Zheng, P., Zhang, X. X., BunNeY, B. S., AND SHI, W. X. Opposite modulation of cortical $N$-methyl-D-aspartate receptor-mediated responses by low and high concentrations of dopamine. Neuroscience 91: 527-535, 1999.

Zhou, F.-M. And Hablitz, J. J. Dopamine modulation of membrane and synaptic properties of interneurons in rat cerebral cortex. J. Neurophysiol. 81: 967-976, 1999. 